\title{
Castillos, poder feudal y reorganización espacial en la Transierra madrileña (siglos XII-XIII)
}

\author{
IÑAKI MARTín VISO *1
}

\begin{abstract}
RESUMEN
Algunos castillos de la Transierra madrileña en los siglos XII y XIII son herederos de los hușün musulmanes, pero se convierten en esa época en centros de poder señorial sobre unas

débiles comunidades. No obstante, sólo su transformación en concejos permitirá la supervivencia de algunos de ellos, aunque se observa también un desplazamiento del hábitat hacia el llano, resultado de la formación de un nuevo sistema productivo basado en la agricultura cerealística y la propiedad feudal, por lo que el papel de los castillos es limitado. En las zonas serranas su relevancia es aún menor y nunca estructuraron el paisaje, labor que ejercieron los sexmos de la Tierra de Segovia.
\end{abstract}

ABSTRACT

Some castles of the Madrid's Transierra in the $x \|^{\text {th }}$ and $x \|^{\text {th }}$ centuries are inheritors of the muslim hușun, but they were converted during this age in centres of a lordship power which was imposed to the weak communities. However, only some of them could survive through their conversion in town councils (concejos), although there is also an habitat's displacement to the plain, that is the result of the new producing system based on the grain agriculture and the feudal property, so the role of the castles was reduced. In the mountain areas the landscape was never structured by castles, but by the rural districts (sexmos) of the Segovia's Land.

* Universidad Nacional de Educación a Distancia.

1 Este trabajo se ha realizado gracias a una beca postdoctoral de la Comunidad de Madrid dentro del proyecto «Poblamiento y territorio en la región de Madrid (siglos X-XIII)". Se utilizan las siguientes abreviaturas: AVI: GamBra, A., Alfonso VI. Cancillería, curia e imperio, León, 1998; AVIII: GonzÁLez, J., El reino de Castilla en la Época de Alfonso VIII, Madrid, 1960; DCMS: VILLAR GaRcia, L.M., Documentación medieval de la catedral de Segovia (1115-1300), Salamanca, 1990; 
El objeto del presente estudio es el análisis de los castillos en un espacio «reconquistado». Este proceso supone la conquista militar por parte de los cristianos de áreas hasta entonces insertas en el conjunto de alAndalus, muchas de las cuales en realidad jamás habían estado en manos de las formaciones políticas del norte peninsular. El concepto de «reconquista» es, por tanto, una creación ideológica que interpreta, desde la clave de los vencedores, una agresión sobre zonas ajenas a los reinos cristianos. Existe una oposición de fondo entre dos sistemas sociales diferenciados: uno tributario, el andalusí, donde el aparato central de poder se relacionaba con las comunidades de campesinos mediante la articulación del tributo, sin la presencia de una clase social aristocrática rentista; otro feudal, el cristiano, en el que las relaciones de producción están poderosamente influidas por la existencia de derechos señoriales sobre el campesinado, que interfieren la relación entre el poder central y las comunidades ${ }^{2}$. Teniendo en cuenta simplemente el aspecto militar de la conquista, los castillos ocupan un papel primordial por su carácter de centros neurálgicos de la defensa del territorio. Pero si se acepta el trasfondo social que está en el origen del fenómeno de la «reconquista», los castillos, lejos de constituir una suerte de mera línea fronteriza, se convierten en elementos de primer orden en la reorganización feudal de un nuevo espacio ${ }^{3}$.

El castillo no es el único elemento que permite la configuración del nuevo espacio feudal. No obstante, su preeminencia en el paisaje social se relaciona siempre con los mecanismos utilizados por los grupos de poder para establecer su control. Fuera de los castillos existen también aldeas, espacios campesinos, zonas de uso comunal, etcétera ${ }^{4}$. Pero no

FII: GonzÁlez, J., Reinado y diplomas de Fernando III, Córdoba, 1980-86; OMS: MARTín, J.L., Orígenes de la orden militar de Santiago (1170-1195), Barcelona, 1974; PRCT: GaRCÍA LUJÁN, J.A., Privilegios reales de la catedral de Toledo (1086-1462), Toledo, 1982; SJ: Ayala MARTínez, C. de (comp.), Libro de privilegios de la Orden de San Juan de Jerusalén en Castilla y León (siglos Xil-XV), Madrid, 1995.

2 GuICHARD, $P_{\text {, « }}$ El problema de la existencia de estructuras de tipo «feudal» en la sociedad de al-Andalus (el ejemplo de la región valenciana)», en VV.AA., Estructuras feudales y feudalismo en el mundo mediterráneo, Barcelona, 1984, pp. 117-138.

3 El primer tipo de análisis, del que hay abundantes ejemplos, parece considerar únicamente las razones geo-estratégicas, a veces nada ciaras, por lo que ciertos autores hablan de un "síndrome Maginot". Vid. Bazzana, A., Maisons d'al-Andalus. Habitat médiéval et structures du peuplement dans l'Espagne orientale, Madrid, 1992, especialmente, vol. 1, p. 388.

4 Barceló, M., "Los husūn, los castra y los fantasmas que aún los habitan», en MaLPICA, A. (ed.), Castillos y territorios en al-Andalus, Granada, 1998, pp. 10-41. No se pretende aquí realizar un estudio exhaustivo de los procesos de trabajo campesino, pero nos parece indudable la importancia fundamental de éstos y de la perspectiva que adopta el referido autor. Por tanto, es éste un estudio dedicado sólo a las formas de poder, sobre todo por las dificultades que aún existen para interpretar adecuadamente los procesos de trabajo campesino. 
cabe duda de que la influencia de las fortalezas, como centros del poder señorial, es evidente. En consecuencia, no se pretende un mero estudio tipológico de las estructuras constructivas de los castillos, sino sobre todo su función dentro de las formas de control social. En este sentido, una cuestión de interés es su relación con el incastellamento, proceso bien estudiado en Italia y que se ha propuesto como una de las claves explicativas del denominado «feudalismo mediterráneo», en el que se englobaría el conjunto peninsular ${ }^{5}$. Las reflexiones sobre este fenómeno son escasas en la península ibérica ${ }^{6}$. En general se niega que el incastellamento fuera un proceso realmente activo en las zonas del noroeste ${ }^{7}$, aunque parece aceptarse en el caso catalán ${ }^{8}$ y se ha supuesto en Navarra un proceso similar en las zonas conquistadas a los musulmanes ${ }^{9}$.

Por otra parte, no hay que olvidar que la sociedad andalusí generó también fortificaciones y que la posterior construcción social feudal se basó, aunque sólo fuera para destruirla, en la estructura espacial previa, que dejó una huella, más honda en los primeros tiempos de la «repoblación», es decir, de la colonización cristiano-feudal de los espacios conquistados, que en fechas posteriores. Ahora bien, la distinta articulación social dotaba a los espacios de un conterido distinto, que no se conservó tras la colonización cristiana, donde las transformaciones son muy profundas.

Si el objeto de análisis son los castillos y su relación con las fuerzas sociales y con la reorganización del espacio, el área elegida es la Transierra madrileña. Se trata de un espacio sin personalidad propia durante estos siglos. En época musulmana no era más que una parte de la Marca Media (al-tagr al-awsat), cuyo centro era Toledo. Tras la conquista, formaba parte del reino de Toledo, pero en su interior convivían instancias señoriales muy variadas, sin que hubiera uniformidad interna ni una delimitación nítida de este espacio, que pertenecía a la Transierra. De hecho, Madrid no

\footnotetext{
5 Toubert, $P$. , «Les féodalités méditerranéennes: un probléme d'histoire comparée», en Structures féodales et féodalisme dans l'occident méditerranéen ( $x^{e}$-Xlle siècles), Roma, 1980, p. 7.

6 A pesar de las afirmaciones de GLICK, T.F., From muslim fortress to christian castle. Social and cultural change in medieval Spain, Manchester, 1995, pp. 106-107 acerca del impacto del debate sobre el incastellamento en el desarrollo de la investigación sobre la península ibérica, parece claro que sólo incide en los estudios sobre al-Andalus, curiosamente una sociedad que difícilmente puede sufrir, por su carácter no feudal, un proceso de ese tipo. Más acordes con la realidad de los espacios cristianos son las reflexiones de FARIAS ZURITA, V., "Acerca de la génesis de las aldeas mediterráneas», Historiar, 4, 2000, pp. 84-98.

7 Mínguez, J.M.a, «El incastellamento, veinte años después», en BARCel_ó, M. y TouberT, P. (eds.), L'incastellamento, Roma, 1998, pp. 7-12.

8 Bonnassie, P., Cataluña, mil años atrás, Barcelona, 1988.

9 LARREA, J.J., La Navarre du wo au x I $^{\circ}$ siècle. Peuplement et société, París-Bruselas, 1998.
} 
es más que una creación del siglo xIX en correspondencia con la formación de la capitalidad del estado liberal. Esta indefinición y heterogeneidad puede ser, sin embargo, de enorme utilidad, ya que muestra comportamientos diferentes en un marco no muy extenso (unos $8.000 \mathrm{kms} .^{2}$ ), lo que permite observar y analizar los fenómenos a través de distintos prismas. De todos modos, hay que ser conscientes de la artificiosidad del territorio elegido, al menos en la Edad Media, que se hace más evidente por la necesidad de introducir algunos castillos muy cercanos a los límites de la región, pero externos a ella, como Olmos, Oreja y Uceda, en las actuales provincias de Toledo y Guadalajara, que intervienen en el desarrollo histórico de la Transierra madrileña.

Los trabajos de P. Guichard, A. Bazzana y P. Cressier ${ }^{10}$ acerca de los castillos andalusíes (hușūn) y su relación con el territorio han proporcionado un modelo sobre el espacio rural que ha roto con los esquemas preestablecidos. El centro castral sería el eje de un territorio subordinado, en el que se inscriben formas de poblamiento como las alquerías (qurà), en manos de la comunidad, con una fuerte dispersión y sin una delimitación nítida de sus confines, así como rahals, que corresponden a propiedades aristocráticas. Éstas últimas pueden llegar a constituir el patrimonio de una aristocracia latifundista, en términos siempre relativos, pero nunca rentista, sino firmemente vinculada al aparato central del estado. El territorio resultante no surge de la iniciativa del poder central, sino de la organización de las comunidades campesinas que fueron las creadoras de los hușūn, al menos en su mayor parte. La toponimia de estos centros en la región valenciana (Sharq al-Andalus) es mayoritariamente prerromana, frente a lo que sucede con las alquerías, lo que probaría una cierta antigüedad del modelo revitalizado en época musulmana ${ }^{11}$. Los hușūn son ti-

10 Bazzana A., Cressier, P. y Guichard, P., Les châteaux ruraux d'al-Andalus. Histoire et archéologie des hușūn du sud-est de l'Espagne, Madrid, 1988. GuicharD, P., «El problema de la existencia»; idem, Les musulmans de Valence et la Reconquête (XI-XIII siècles), Damasco, 1990; idem, "La formación de al-Andalus", en MALPICA A. y QUESADA T., Los origenes del feudalismo en el mundo mediterráneo, Granada, 1995, pp. 57-67. BAZZANA, A., «Typologie: les habitats fortifiës du Sharq al-Andalus", en Castrum 1: Habitats fortifiès et organisation de l'espace en Méditerranée médiévale, Lyon, 1983, pp. 19-27; idem, «Hisn et territoire dans l'organisation du peuplement islamique dans al-Andalus», en BARCeló, M. y TouBert, P. (eds.), L'incastellamento, pp. 179-204. Cressier, P., "Fonction et évolution du réseau castral en Andalousie orientale: le cas de l'Alpujarra", en Castrum 3. Guerre, fortification et habitat dans le monde méditerranéen au Moyen Âge, Madrid, 1988, pp. 123-134; idem, "Remarques sur la fonction du château islamique dans l'actuelle province d'Almeria à partir des textes et de l'archeologie», en BARCELÓ, M. y TOUBERT, P. (eds.), L'incastellamento, pp. 233-248.

11 Según M. Acién Almansa, la formación de hūsunn en la zona meridional de la península estaría relacionada en buena medida con la conformación de grupos aristocráticos protofeudales 
pológicamente variados, pero responden en general a las necesidades de defensa de unas comunidades campesinas no militarizadas, donde juega un papel relevante el albácar como centro de refugio de la población. El poder central se limita a establecer una vinculación con las comunidades, instituyendo la figura de un alcaide en los centros más importantes; se trata de un delegado del poder central, sin posibilidades de actuar autónomamente y que debe reconocer que son las comunidades las que poseen en realidad estos centros fortificados. De esta manera, el modelo de hișn se inserta sin problemas en la sociedad tributaria y segmentaria que se defiende para al-Andalus.

Este modelo, descrito aquí muy someramente, ha supuesto un enorme avance en la investigación, ya que además ha venido acompañado por una reconsideración general sobre la sociedad andalusí. No obstante, las investigaciones que se están llevando a cabo ponen de relieve la rigidez del mismo. Los estudios realizados por $\mathrm{H}$. Kirchner en Mallorca revelan que pueden existir redes de alquerías sin husūn y que estos tienen en ocasiones funciones muy limitadas, lejos de la centralidad otorgada por los estudios ya señalados ${ }^{12}$. Por otra parte, los husșūn son extremadamente variados, no sólo en su tipología constructiva, sino en relación con las comunidades, y no se debe excluir la influencia del aparato estatal andalusí en la conformación de algunos de estos lugares, que no responden a la lógica de los espacios creados por las comunidades. También debe destacarse la excepcionalidad de la región valenciana, tomada como ejemplo de este modelo, donde la red de hușūn es muy densa, circunstancia que responde a una realidad tardía, inmediatamente anterior a la conquista cristiana del segundo tercio del XIII. Se ha supuesto que, ante la debilidad del poder central, las propias comunidades campesinas respondieron mediante la fortificación, creando incluso alquerías fortificadas, con el objetivo de buscar un pacto de rendición que impidiera su expulsión por parte de los cristianos ${ }^{13}$. Lo cierto es que otras áreas, como la región de

entre la población mozárabe y por las luchas generadas con la fitna de finales del siglo IX y principios del $x$. Vid. «Poblamiento y fortificación en el sur de al-Andalus. La formación de un país de hușūn", en III Congreso de Arqueơlogía Medieval Española, Oviedo, 1989, vol. I, pp. 135-150 y Entre el feudalismo y el Islam. Umar lbn Hafsun en los historiadores, en las fuentes y en la historia, Jaén, 1994.

12 "Husuun y alquerías campesinas en las islas orientales de al-Andalus», en BARCELó, M. y TOUBERT, P. (eds.), L'incastellamento, pp. 249-269 y «Redes de alquerías sin hușūn. Una reconsideración a partir de los asentamientos campesinos andalusíes de las islas orientales", en MALPICA, A. (ed.), Castillos, pp. 450-469.

${ }_{13}$ TORRÓ, J., "Fortificaciones en Yibal Balansiya. Una propuesta de secuencia», en MALPICA, A. (ed.), Castillos, pp. 385-418. 
Huesca ${ }^{14}$, responden a una red mucho menos densa, algo que también ocurre en la Transierra madrileña.

Determinados hușūn en la región madrileña son el resultado de una política auspiciada por el aparato central andalusí. Se conocen las fundaciones o fortificaciones de algunos centros, como Madrid, Talamanca y Calatalifa (Villaviciosa de Odón). Los dos primeros debieron ser objeto de dicho proceso durante el emirato de Muhammad I hacia el año $860{ }^{15}$, mientras que Calatalifa (Qal'at Jalifa=castillo del califa) es fortificada por Abd al-Rahman III en el año $940^{16}$. Las razones de esta política parecen ser variadas. En primer lugar, se pretendía fortalecer una zona fronteriza que podía ser atacada por los ejércitos cristianos ${ }^{17}$. Talamanca controlaba la ruta del Jarama, Madrid la del Manzanares y Calatalifa la del Guadarrama. En este contexto parece coherente la creación de un sistema de atalayas, orientado hacia el norte y que delimitaba el espacio bajo control andalusí ${ }^{18}$. Su pertenencia al entramado de poder andalusí es muy evidente, ya que

14 SÉnAC, P., «Du hișn musulman au castrum chrétien. Le peuplement rural de la Marche Supérieure et la Reconquête aragonaise", en LALIENA CoRBERA, C. y UTRILLA UTRILLA, J.F. (eds.), De Toledo a Huesca. Sociedades medievales en transición a finales del siglo Xi (1080-1100), Zaragoza, 1998, pp. 113-130.

15 Así lo señala Ibn Hayyan. Vid. Manzano Moreno, E., La frontera de al-Andalus en época de los omeyas, Madrid, 1991, p. 168.

16 VIGUera, M. a J. y CoRRIENTE, F., eds., Crónica del califa 'Abdarrahman III an-Nasir entre los años 912 y 942 (al-Muqtabis V), Zaragoza, 1981, 309.

17 Es el caso de la campaña del año 860 de Ordoño I contra Talamanca, donde apresó a su reyezuelo o la del año 932 de Ramiro II contra Madrid o la victoria del año 940 en la zona de Talamanca sobre un ejército cristiano. Vid. "Crónica albeldense», en GIL FERNÁNDEZ, J. et alii, Crónicas asturianas, Oviedo, 1985, XV, 11; PĖREz DE URBEL, J. (ed.), Sampiro. Su crónica y la monarquía leonesa en el siglo X. Madrid, 1959, 22; Al-Muqtabis V. 307. Sobre la función geoestratégica, véase GonzÁlez, J., Repoblación de Castilla la Nueva, Madrid, 1975, vol. I, pp. 34-53; ZOZAYA, J., "El Islam en la región madrileña", en Madrid del siglo $I X$ al XI, Madrid, 1990, pp. 195203; Sáez lara, F., Malalana, A. y Martinez Lillo, S., «Poblamiento y red viaria en la Marca Media. Un comienzo de aproximación", en // Congreso de Arqueología Peninsular, Zamora, 1999. vol. IV, pp. 537-554.

${ }_{18}$ Se conocen los restos de las atalayas de El Vellón, Venturada, Arrebatacapas (Torrelaguna) y El Berrueco en la zona del Jarama, al norte de Talamanca, y posiblemente hubiera dos más en Torrelaguna y El Molar, todas ellas en relación con el tagr de Talamanca. En la zona de la Sierra de Hoyo del Manzanares estarían las de Torrelodones y Collado de la Torrecilla, vinculadas a Madrid y/o Calatalifa. Todas ellas presentan ciertas similitudes constructivas y debieron levantarse en el siglo $x$ con el apoyo de las comunidades locales, pero bajo la iniciativa omeya. Vid. Caballero, L. y Mateo, A., "El grupo de atalayas de la sierra de Madrid", en Madrid del siglo IX al XI, pp. 65-77; SAEZ LARA, F., «Catálogo de los castillos, fortificaciones y recintos amurallados medievales de la comunidad de Madrid», en Castillos, fortificaciones y recintos amurallados en la comunidad de Madrid, Madrid, 1993, pp. 114-125; Malalana Ureña, A., Martínez Lillo, S. y SÁez LARA, F., "La ruta del Jarama y su entorno en época andalusí», en Segura Graíño, C. (ed.), Orígenes históricos de la actual comunidad autónoma de Madrid. La organización social del espacio en la Edad Media, l, Madrid, 1995, pp. 154-164; Retuerce Velasco, M., «Carta arqueológica de la meseta andalusí según el referente cerámico», BEM, 8, 1994, p. 45. 
existen gobernadores omeyas en Madrid y Talamanca en el siglo $\mathrm{x} y$ Calatalifa es una base de operaciones para las aceifas hacia el norte ${ }^{19}$. Otros autores han postulado una razón diferente, la formación de una línea fortificada que aislara a la revoltosa Toledo, en conflicto permanente con el poder omeya en los siglos $\mathrm{I}$ y y principios del $\mathrm{x}$. Apoyándose en los beréberes de la zona (los banu Salim), leales a Córdoba, se estableció una organización de fortines que actuaba a modo de frontera interior ${ }^{20}$. Pero aún siendo importantes estos factores, también hay que considerar que la iniciativa omeya tenía como objetivo básico, que permite la obtención de los otros, la consecución del control efectivo sobre una zona hasta entonces poco dominada por los omeyas. Formar centros desde los cuales establecer el entramado tributario y consolidar la vinculación de los poderes beréberes de la zona con Córdoba era una finalidad esencial para el éxito de cualquiera de las otras opciones «geoestratégicas». El hecho de controlar las rutas es importante para la selección de estos centros, pero más aún lo es el dominio sobre áreas de fuerte potencialidad agraria, que podían generar un importante tributo ${ }^{21}$.

De todos modos, hay indicios de estructuras previas. En Talamanca se han hallado restos que se identifican con el período visigótico ${ }^{22}$, mientras las excavaciones en Calatalifa arrojan la presencia de cerámica andalusí del siglo IX, lo que se corresponde con la preexistencia del lugar antes de su fortificación ${ }^{23}$. Más conflictivo es el caso de Madrid, donde el registro arqueológico no ha proporcionado datos sobre un asentamiento previo, siendo indudable la impronta ideológica de ciertos estudios que pretendían negar el carácter musulmán de este núcleo ${ }^{24}$. De hecho,

19 Al Muqtabis V, 293.

20 El principal defensor de esta teoría es Manzano Moreno, E., La frontera, pp. 168-170 y 305.

21 Así en las inmediaciones de Madrid existen aldeas medievales con nombres claramente árabes, quizás herederas de las qurà, como Carabanchel, Alcobendas, Alcorcón y Getafe, donde pudo haber una alquería en el término de La Aldehuela. Se conoce además un yacimiento de esta época en el aeropuerto de Barajas, que debia responder a este modelo (RETUERCE VELASCo, M., “Carta arqueológica», pp. 43-44). En las cercanías de Talamanca existían en 1580 cuatro aldeas despobladas con claros nombres árabes: Alberrache, Ballunquera, Espartal y Aristón; TORRES BALBÁs L., «Talamanca y la ruta olvidada del Jarama», BRAH, CXLVI, 1960, pp. 237-238.

22 LANDETE, M.J., "Los restos arqueológicos en Talamanca de Jarama», Revista de Arqueología, 18, 1982, pp. 6-9; HeRmidA, M. a C., GómEZ, L. y ARÉVAlo, A.I., «Talamanca del Jarama en la Edad Media», AIEM, XXX, 1991, pp. 423-430; SÁEZ LARA, F., «Catálogo», pp. 223-226.

23 RetueRce VelasCo, M., «La cerámica islámica de Calatalifa: apuntes sobre los grupos cerámicos de la Marca Media", Boletín del Museo Arqueológico Nacional, Il, 1984, pp. 117-136; PÉrez VICENTE, D., «Excavaciones arqueológicas en Calatalifa», en Madrid del siglo IX al XI, pp. 141-144; SÁEZ LARA, F., «Catálogo», pp. 146-147.

24 CABAllero ZOREDA, L. et alii, «La muralla de Madrid. Excavaciones y estudios arqueológicos (1972 a 1982)», EPAM, 2, 1983, pp. 14-16; Segura Graiño, C., "Madrid en la Edad Media. 
MAPA 1. HUSSUUN Y POBLADOS EN ALTURA (SIGLOXI)

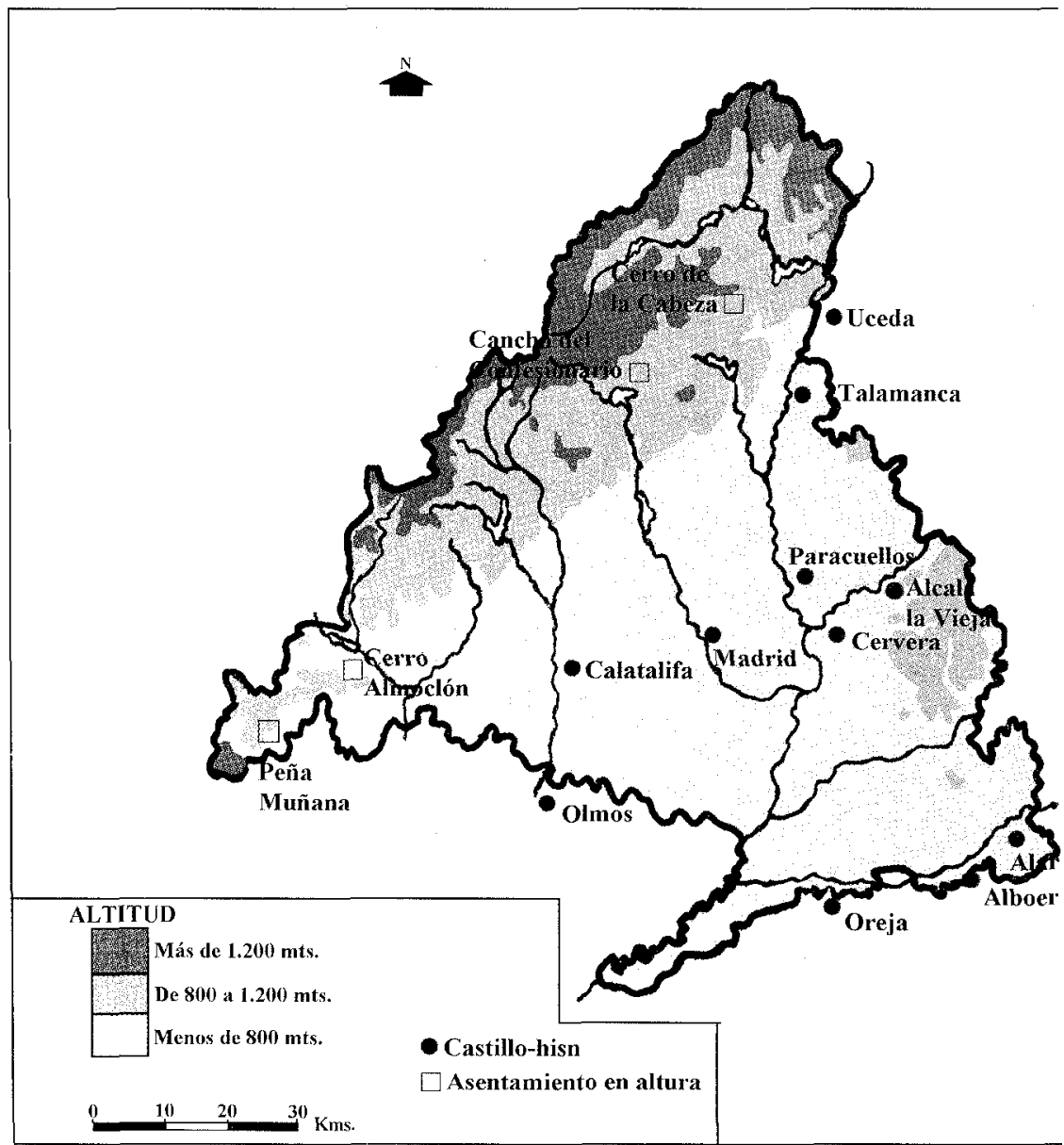

Madrid sirve como metáfora para el resto de los casos, ya que no se trata de un mero reaprovechamiento de las estructuras previas, sino de una transformación total del contenido de aquéllas. Los hușūn, algunos de los cuales, como Madrid, derivarán en ciudades (madīna), son núcleos con nuevas funciones que jerarquizan el espacio, crean territorios subordina-

Génesis de una capital 873?-1561)", en JuliÁ, S., Ringrose, D. y Segura, C., Madrid, historia de una capital, Madrid, 1995, pp. 17-25. 
dos y se hallan en la órbita primero de los omeyas y después de la taifa toledana. Son nódulos del poder central. Es posible que Olmos (U/ms) responda a esa doble condición de organización del espacio agrario y dominio del poder central ${ }^{25}$.

Un caso similar es el de Alcalá (Qal'at abd-al-Salam), cuya fundación se debió producir hacia el siglo Ix, sustituyendo al antiguo centro visigodo de Complutum. Dejando de lado la posible permanencia de población en el antiguo núcleo, lo cierto es que se genera un nuevo núcleo, como lo demuestra el topónimo, claramente árabe ${ }^{26}$, en el que se combinan las necesidades defensivas y la existencia de un asentamiento civil ${ }^{27}$. La posible función de control de la cuenca del Henares y la vía hacia Zaragoza tendría como principal eje a Guadalajara. No hay que desestimar el hecho de que esta fortificación se levante en una zona de intensa actividad agraria, donde se habían concentrado varias villae tardorromanas ${ }^{28}$ y en una zona en la que se advierte de la presencia de numerosas alquerías, conocidas por la arqueología o por la toponimia ${ }^{29}$. Es muy probable que hubiera una consolidación del modelo de hișn en esta zona a partir del siglo Ix mediante una «tribalización" de las comunidades, ya que no parece tratarse del centro principal del dominio omeya en la zona. Muy similares serían los pequeños centros de Ribas y Cervera ${ }^{30}$, posiblemente insertos en el terri-

25 Esta fortaleza se halla en El Viso de San Juan (Toledo) con una ocupación ya existente en el siglo IX. MARTínez LiLLO, S., «Primeros materiales arqueológicos del castillo de Olmos. El Viso de San Juan (Toledo)», en / Congreso de Historia de Castilla-La Mancha, Ciudad Real, 1988, vol. V, pp. 95104; idem, «El poblado fortificado de Olmos (Walmus)», en Madrid del siglo $I X$ al $X I$, pp. 131-140.

26 ACIÉN, M., «La fortificación en al-Andalus», Archeologia Medievale, XXII, 1995, pp. 11-12 considera que las fortificaciones denominadas qal'at serían asentamientos nuevos creados por los conquistadores.

27 TORRES BALBÁs, L., «Estudios de arqueología e historia urbana. Complutum, Qal'at'abd-alSalam y Alcalá de Henares», BRAH, CXLIV, 1959, pp. 155-188; PAvón, B., Alcalá de Henares medieval. Arte islámico y mudéjar, Madrid 1982, pp. 52-60; ZOZAYA, J., «Excavaciones arqueológicas en Qalat Abd-al-Salam (Alcalá de Henares)», NAHisp, 17, 1983, pp. 411-529; TURiNA, A., «El castillo de Alcalá de Henares", en Madrid del siglo Ix al Xl, pp. 189-194; SÁEZ LARA, F., "Catálogo", pp. 92-95.

28 GoRgES, J.G., Les villas hispano-romaines. Inventaire et problemátique archéologiques, Madrid, 1979, pp. 300-302.

29 Se ha excavado el yacimiento de «Las Fuentecillas», en San Fernando de Henares, que sería una qarya, que presenta una ocupación entre los siglos Ix al XII. Vid. BERMEJo CRESPO, J.L. y MUÑoz LóPEZ-ASTILlERos, K., «Una explotación agrícola en el territorio de los Banu Salim: excavaciones en «Vereda de Sedano" o «Las Fuentecillas" (San Fernando de Henares, Madrid)», $B E M, 8,1994$, pp. 205-225; idem, «El yacimiento medieval de "Vereda de Sedano" o "Las Fuentecillas" (San Fernando de Henares, Madrid). Campañas de excavaciones de 1989 y 1990", EPAM, 10, 1995-96, pp. 111-119. En la confluencia entre el Henares y el Jarama se conocen los núcleos despoblados hacia el siglo xv de Daralcalde. Aldovea y Vaciabotas, todos ellos de origen árabe; TORRES BALBÁs, L., «Talamanca», p. 237.

30 Pavon Maldonado, B., "Las fortalezas islámicas de Ribas de Jarama y Cervera (Madrid)": AIEM, XVII, 1980, pp. 19-24; SÁEZ LARA, F., «Catálogo», pp. 206-207; RetuerCe Velasco, M., "Carta arqueológica», pp. 47-50. Ambos parecen estar ocupados desde el siglo IX. 
torio (iqlim) de Madrid, pero quizás en relación con la actividad de las comunidades campesinas de la zona. Su cercanía a los cursos fluviales del Henares y el Jarama no respondería a una decisión estratégica del poder central, sino de las propias comunidades en relación con las necesidades de agua de la zona. Un caso similar debió ser el de Uceda, población alejada de posibles rutas geoestratégicas, pero que controla una zona de vega del río Jarama, en torno a Patones y Torrelaguna. Se han hallado restos cerámicos musulmanes en su castillo, situado en un cerrete separado actualmente de la población ${ }^{31}$. En este caso se aprecia una posible relación con formas castrales de organización del espacio, ya que se domina igualmente el altiplano que se levanta desde Uceda hacia el sur, muy apropiado para los pastos, generando una economía complementaria entre ganadería y agricultura ${ }^{32}$.

Pero si estos hușün parecen corresponder a una agrupación campesina, vinculada mediante otros centros al poder andalusí (Madrid, Guadalajara), los castillos más meridionales sugieren otras hipótesis. Así, Oreja, Alboer y Alarilla se encuentran dominando la ribera del Tajo que en esta zona es relativamente abrupta, sin permitir zonas de vega ${ }^{33}$. Siguen la estructura de un asentamiento fortificado, pero su origen puede ser más tardío, al menos en el caso de Oreja, donde los materiales cerámicos más tempranos son del siglo $\mathrm{XI}^{34}$. Es posible que la cerámica únicaniente nos esté dando una información sobre el poder central. En cualquier caso, tampoco figura en la documentación escrita hasta el período cristiano. Son pequeños asentamientos, probablemente muy relacionados con zonas más al sur, implantados por la lógica del poder central, que busca el control sobre el Tajo, bien por motivos militares, bien por motivos fiscales.

Se observa, por tanto, una notable heterogeneidad y una dudosa eficacia geoestratégica, que sólo interviene en determinados casos y de ma-

\footnotetext{
31 Retuerce Velasco, M., «Carta arqueológica», p. 42.

32 Sobre la articulación de los castros en la actividad de las comunidades campesinas del norte peninsular, vid. MARTín VISO, I., Poblamiento y estructuras sociales en el norte de la península ibérica (siglos VI-XIII), Salamanca, 2000 y FERNÁNDEZ MIER, M., Génesis del territorio en la Edad Media. Arqueologia del paisaje y evolución histórica en la montaña asturiana, Oviedo, 1999.

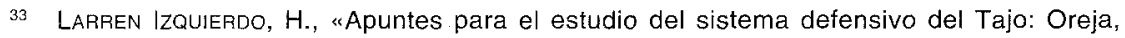
Alarilla y Alboer», BEM, 2, 1988, pp. 87-95; "El castillo de Oreja (Toledo)», en Madrid del siglo IX al XI, pp. 105-114; SÁEZ LARA, F., “Catálogo», pp. 88-91; RetuerCe VELASCO, M., "Carta arqueológica», pp. 43-44, 46 y 65.

34 Retuerce Velasco, M., La cerámica andalusi de la meseta, Madrid, 1998. Alarilla y Alboer sólo presentan cerámicas del siglo $x$ en adelante.
} 
nera muy distinta a la que se había sostenido, debido a que lo importante no es tanto el control frente al extraño, sino el dominio efectivo de unas comunidades, las cuales podían estar ya ocupando estos centros, quizás con la excepción de Madrid. Las relaciones con el poder son muy dispares y también con el territorio. Se puede hablar de dos tipos de funciones que emanan del hișn. Por un lado, las que se establecen desde la lógica del estado: control político de la zona, establecimiento de tributo y consolidación de un asentamiento de carácter «urbano», cuya máxima expresión es Madrid. Por otro, las generadas desde las comunidades campesinas, a veces instigadas por grupos beréberes: defensa de unas comunidades autónomas respecto del estado, control de los espacios irrigados y formación de pequeños asentamientos de una mayor importancia que las qurà, pero sin llegar al status de madina. La diferente intensidad de estas funciones afecta a la heterogeneidad de los hușūn y a su propio desarrollo posterior. En el siglo XI, el aumento del peligro cristiano debió favorecer el desarrollo de Madrid como centro neurálgico del poder central toledano. En cambio, otros centros mantuvieron unas funciones muy similares, pero se integraron en el dominio madrileño, como quizás ocurrió con Ribas ${ }^{35}$. Las fortalezas meridionales comenzaron a crecer, sin que ello supusiera un considerable aumento de su capacidad de integración de los territorios situados entre el Tajuña y el Tajo.

A pesar del desarrollo del modelo de hișn, existen áreas dentro de la Transierra madrileña que no poseen una organización similar. Una de ellas corresponde a los espacios situados en el piedemonte serrano y en el Sistema Central. Configuran un arco que va del nordeste al suroeste donde se encuentran las tierras más altas de la región. Sus condiciones geográficas se adaptan mejor a la ganadería, con rutas trashumantes que pasan por sus tierras ${ }^{36}$. Es también un espacio que parece situarse fuera del control andalusí, como lo comprueba la localización de las atalayas, que tendría una relación más estrecha con los sectores más meridionales de la Extremadura castellano-leonesa como Ávila y Segovia, igualmente poco o nada dominados por las formaciones políticas cristianas. En algunos puntos de esta zona se desarrolla un modelo de poblados en alto, sobre todo en la zona del Real del Manzanares (Cancho del Confesio-

35 Ribas aparece a mediados del XII dentro del término de Madrid: «illo castello quod est in termino de Maiarid et vocatur Ribas»; PRCT, doc. 20 (1154.07.11). No obstante, cabe plantear dudas acerca de si esta situación se puede retrotraer al período musulmán.

36 La ganadería ya era conocida en época musulmana, según el testimonio de Al-Himyari; GLıck, T.F., Cristianos y musulmanes en la España medieval (711-1250), Madrid, 1991, p. 135. HERNÁNDEZ JIMÉNEZ, F., «La travesía de la Sierra de Guadarrama en el acceso a la raya musulmana del Duero», Al-Andalus, XXXV1II, 1973, pp. 69-185 y 415-454. 
nario), sierra de la Cabrera (Cerro de la Cabeza) y en el curso del Alberche (Peña Muñana y Cerro Almoclón) ${ }^{37}$. Son pequeños núcleos situados en altura, con defensas muy rudimentarias que complementan las condiciones naturales, con un reducido espacio de hábitat, que se relacionan con el control de pasos ganaderos y con la propia articulación de espacios menores destinados a esa actividad, donde habría una pequeña trashumancia local. Se asemejan a los poblados «encaramados» que se han localizado en otras áreas y que se han puesto en relación con la actividad campesina durante los siglos $\mathrm{VI}$ en adelante ${ }^{38}$, como se observa en «El Cancho de El Confesionario» (Hoyo de Manzanares), cuyo origen se remonta a la época visigótica. Es notoria la influencia andalusí, como se observa en la presencia de restos cerámicos, si bien la ausencia de elementos como la cerámica vidriada, propia de grupos dirigentes cercanos a la estructura del poder central, nos sitúa ante unas comunidades con una cierta capacidad de autonomía. Este tipo de hábitat, al que quizás habría que añadir otros posibles hallazgos, convive con otro disperso e inestable, íntimamente ligado a la explotación ganadera de estos territorios. Es muy probable que hubiera una intervención por parte de las comunidades extremaduranas, en especial Segovia, que serían la base de su posterior expansión.

Otra zona donde se detecta la ausencia de hușūn es la situada al sudeste de la región, en un triángulo formado por los cursos fluviales del Henares, el Jarama, el Tajuña y el Tajo. Al contrario que en los sectores serranos, estamos ante una zona de ocupación andalusí con amplios recursos agrícolas, en especial las vegas de los ríos. Aquí se observa la existencia de redes de alquerías sin hușūn. Así, en "La Marañosa" (San Martín de Vega) o en Valderradelas (Chinchón) ${ }^{39}$ el registro arqueológico nos muestra la presencia de qurà situadas sobre cerretes, pero sin que

37 Caballero Zoreda, L. y Megias Pérez, G., «Informe de las excavaciones del poblado medieval del Cancho del Confesionario, Manzanares el Real (Madrid)», NAHisp, 5, 1977, pp. 325-332; SAez LARA, F., «Catálogo», pp. 78-79 y 144-145.

38 Vid. Acién Almansa, M., «La fortificación», Gutiérrez Lloret, S., La Cora de Tudmir, de la Antigüedad Tardía al mundo islámico. Poblamiento y cultura material, Madrid, 1996, pp. 275 y ss. y Castillo Armenteros, J.C., La campiña de Jaén en época emiral (s. vili-x), Jaén, 1998. Este «encaramamiento" se ha observado también en diversas áreas de la península italiana, como Calabria, Cerdeña o Toscana. De todas formas, la aplicación de este modelo ha sido criticada recientemente por Barceló, M., "Los hușün, los castra", p. 25 y CARA BARrionuevo, L. y Rodríguez LóPEZ, J.M. ${ }^{2}$, «Introducción al estudio crono-tipológico de los castillos almerienses» en MALPICA, A. (ed.), Castillos, pp. 170 y ss.

39 BARRIL Vicente, M., "Prospecciones en La Marañosa y San Martín de la Vega (Madrid)", AIEM, XIX, 1982, pp. 581-603; RetuerCe VelASCO, M., «Carta arqueológica», pp. 50-51; idem, La cerámica. 
Castillos, poder feudal y reorganización espacial en la Transierra madrileña...

aparezcan elementos defensivos. Su cercanía y control sobre los cursos fluviales estaría en relación con su capacidad para la explotación de las fértiles vegas. Este tipo de poblamiento era básicamente disperso y permanecerá en los siglos XII y XIII a través de los numerosos "valles» que dan lugar a ciertos topónimos. Así sucede con el valle de Salvanés, entre el Tajuña y el Tajo, fuera de cualquier ámbito de influencia de castillo alguno ${ }^{40}$. Es interesante observar la frecuente existencia de topónimos prerromanos (Salvanés), bastante abundantes en el territorio de Alcalá: Tielmes, Arganda, Loeches, Ambite, etcétera ${ }^{41}$. Este dato puede incidir en una cierta continuidad de las explotaciones y de las comunidades, pero sin duda hubo importantes transformaciones en el período andalusí.

Por lo tanto, el panorama que se observa es muy complejo, aunque se adapta siempre a las estructuras sociales tributarias y a la segmentación. El modelo de hișn no era único, pero abarcaba la mayor parte del territorio $y$, sobre todo, se trataba de las zonas mejor controladas por el aparato político central.

La conquista cristiana del territorio se produjo en 1085, cuando cae el reino de Toledo en manos de Alfonso VI. El final de la política de parias conllevó la elección de una opción más agresiva, que incluía la conquista efectiva del territorio, dejando de lado las incursiones de castigo y botín que aún se documentan en la época de Fernando I ${ }^{42}$. La estrategia de los cristianos se vio favorecida por las luchas intestinas dentro de la taifa toledana durante los años 1075 a $1085^{43}$. La conquista de la ciudad de Toledo supuso un fuerte impacto en la mentalidad de los andalusíes: por primera vez caía en manos de los cristianos una ciudad que articulaba un importante sector fronterizo. Con ella, y posiblemente sin violencia, también cayeron las fortalezas que articulaban el espacio de la taifa. Las crónicas cristianas hablan de la ocupación de los lugares de Madrid, Olmos, Talamanca y Uceda y la repoblación de Buitrago en la Transierra madrileña ${ }^{44}$. Se tra-

40 Aparece ya en 1103, en la donación que Alfonso VI realiza a la iglesia de Toledo, texto donde parece describirse un sistema de carácter hidráulico que estaría en la base del territorio, de carácter campesino: "et insuper Val de Salvanes, cum toto suo termino, sicut tendit usque a las Alcarrias cum suis aquis dulcibus salsis et amaris..."; AVI, doc. 174. Otros casos pueden ser los de Valderacete, Rinconada de Perales o más al norte Valdetorres y Valdelecha.

41 Cuando en 1214 Alfonso VIIl restituye una serie de aldeas «in termino de Alcala» al arzobispo de Toledo, un buen número de ellas posee topónimos prerromanos como: Lueches, Bielches, Arganda, Tielmes, Caravanna, Orusco y Henbit; PRCT, doc. 44.

42 Santos Coco, F., Historia Silense, Madrid, 1921, pp. 78-79.

43 Un relato preciso es el de GonzÁLEZ, J., Repoblación, vol. I, pp. 69-83.

44 JimÉnez de Rada, R., Historia de rebus Hispanie sive Historia Gothica (Fernández Valverde, J. ed.), IIII, XI: «Set in finibus regni Castelle Aldefonsus, qui cepit Toletum, cepit etiam Talaveram, 
taba de los puntos principales del dominio toledano, aunque siempre vistos desde la perspectiva cristiana. El control del territorio se establecía a partir de una red de oppida que aparecen en documentos inmediatamente posteriores a la conquista. Así, en 1127 se señalan como pertenecientes al territorio arzobispal de Toledo los oppida de Olmos, Madrid, Alcalá, Uceda, Talamanca y Buitrago ${ }^{45}$ y en 1138 figura también Calatalifa ${ }^{46}$.

Es interesante observar la «repoblación» de Buitrago. Aunque se ha supuesto la ocupación de este lugar en época musulmana, el registro arqueológico no ha proporcionado vestigios que sostengan esa afirmación. Los restos del castillo son posteriores y, a lo sumo, reflejan en algunas zonas la fortaleza del siglo XII ${ }^{47}$. Sin embargo, Buitrago posee un topónimo prerromano y aparece en 1076 en la delimitación del espacio sepulvedano ${ }^{48}$. Ya entonces parece ser algo más que un mero asentamiento, dado que controla un territorio. Su localización en la zona serrana explica en buena medida la ausencia de restos cerámicos islámicos, debido a que se encontraba en una zona influida por el aparato político andalusí, pero no inserta en el mismo. Se sitúa en un recodo del río Lozoya, sobre un pequeño altozano, por lo que podía tratarse, y siempre como hipótesis, de un asentamiento en cerro que controlaba un paso ganadero, que es también una vía de comunicación hacia la submeseta norte ${ }^{49}$. Durante los siglos VIII al XI debió ir consolidando su centralidad en esta comarca donde no hay trazas de ocupación musulmana. Sería una comunidad muy similar a las del norte de la cordillera, como Sepúlveda, cuyos grupos dirigentes fueron asumiendo un papel protagonista en las relaciones sociales, dominando un territorio ${ }^{50}$. Al igual

Maquedam, Sanctam Eulaliam et Alfanum, populavit Scalonam, cepit Mageritum, Canales et Ulmos, Talamancam, Uzetam, Guadalfaiaram, Fitam et Alocariam, populavit Buytragum».

45 FITA, F., «Bula inédita de Honorio II», BRAH, VII, 1885, pp. 335-337.

46 FITA, F., "Madrid en el siglo XII», BRAH, VIII, 1889, doc. 2.

47 López del Álamo, M. ${ }^{a}$ F. y RuBio VISIERS, M. ${ }^{\text {a }}$ J., "Las murallas de Buitrago de Lozoya", en VA.LDÉS, F. (ed.), Mayrit. Estudios de arqueología medieval madrileña, Madrid, 1992 pp. 33-43; SÁEz LARA, F., "Catálogo", pp. 132-143.

${ }_{48}$ AVI, doc. 40: "de Lozoiha usque huc quantum Butrago habuit in sua potestate».

A9 Se ha supuesto que sería el puerto (Fag Tarik) que atravesó Tariq para traspasar la sierra y conquistar Olmedo. IBN ILARI al Marrakusi, Historia de al-Andalus (Fernández González, F., ed.), Málaga, 1999, p. 30; Chalmeta, P., Invasión e islamización. La sumisión de Hispania y la formación de al-Andalus, Madrid, 1994, p. 158.

50 Se ha defendido que quizás hubiera una repoblación hacia el año 940 , cuando se produce la de Sepúlveda, pero no deja de ser una hipótesis; vid. LOMBANA DomínGUEZ, N., «El enclave estratégico de Buitrago de Lozoya y su evolución histórica (siglos $x$ al xv)", en Segura Graiño, C., Origenes históricos, p. 114. Parece que su situación estuvo, de todas formas, muy vinculada a lo que sucede en las zonas más meridionales de la Extremadura castellano-leonesa, también opacas al registro escrito hasta una fecha similar, y donde se estarian creando núcleos que centralizaban 
que los lugares antedichos, la integración en la órbita de Castilla se realizó a través del expediente de la «repoblación», que reconoce su centralidad y el papel de los grupos dirigentes locales, pero que ha de someterse al nuevo poder. Es éste el responsable de la construcción de una nueva fortaleza que sustituye a la primitiva existente, posiblemente realizada en materiales pobres, siguiendo el modelo de asentamientos en alto, y que engloba una nueva villa.

El control de la región madrileña es inestable al menos durante la primera mitad del siglo xII. Los almorávides conquistaron Alcalá la Vieja y Oreja en 1109 y 1113 respectivamente. Desde ambas bases hostigaron de forma continuada el proceso de colonización de la Transierra. En 1118 el arzobispo toledano don Bernardo conseguirá rendir la fortaleza de Alcalá la Vieja, que pasará a su dominio señorial ${ }^{51}$, pero Oreja seguirá siendo un foco de inestabilidad hasta su toma por Alfonso VII en $1139{ }^{52}$. Sólo a partir de ese momento se da un impulso a la colonización señorial del territorio. Dicho proceso se realizó posiblemente con la expulsión de la mayoría de la población autóctona, que optó por marchar del territorio conquistado. La cesión de Alfonso VI de todas las mezquitas de la Transierra y de sus bienes en beneficio del arzobispado de Toledo es un reflejo de la desposesión que sufren los musulmanes ${ }^{53}$. De todos modos, el mantenimiento de buena parte de la toponimia árabe y la existencia de una producción agraria parecen ser elementos que matizan esa desbandada musulmana. Es posible que algunos de los habitantes, sobre todo los de condición social inferior ${ }^{54}$ y algunas posibles pequeñas comunidades mozárabes, permanecieran en la región, aunque la documentación es oscura en este punto.

Un dato que debe tenerse en cuenta es el control de los castillos por la monarquía. La mayor parte de las fortalezas que se conocen en el siglo XII

amplias áreas, al tiempo que se formaba un entramado defensivo en las zonas fuera del control de cualquier aparato político central. Vid. BARRIOS GARciA, Á., "Repoblación de la zona meridional del Duero. Fases de ocupación, procedencias y distribución espacial de los grupos repobladores», SHHM, III, 1985, pp. 55-56; Minguez, J.M. a "La repoblación de los territorios salmantinos", en Martin, J.L., Historia de Salamanca. II. Edad Media, Salamanca, 1997, pp. 27-45.

51 Porres Martín-Cleto, J. (ed.), Anales Toledanos / y II, Toledo, 1993, p. 100; PRCT, doc. $10(1125.02 .10)$.

52 MaYa SÁncheZ, A. (ed.), “Chronica Adefonsi Imperatoris» en Chronica Hispana Saeculi XII. Pars I, II, 50-63.

53 AVI, doc. 101 (1089.11.09).

54 De Miguel, J.C., La comunidad mudéjar de Madrid, Madrid, 1989, pp. 19-23. No obstante, en Toledo los mudéjares parecen ser cautivos liberados o sus descendientes que se crean como grupo con la reconquista del siglo XII; MOLÉNAT, J.P., Campagnes et monts de Tolède du XI/ au Xve siècle, Madrid, 1997, pp. 27-35. 
estaban en manos del rey, aunque muchas de ellas se mencionan por primera vez en el registro escrito precisamente cuando son enajenadas. Esta situación tendría su origen en el control de los hușūn por el poder central, en este caso por la taifa de Toledo. Su rendición en 1085 equivalía a la cesión de los derechos sobre tales núcleos. De esta manera, el monarca castellano se aseguraba el control del territorio del aparato político centralizado. La coyuntura de constantes luchas por el dominio de la Transierra trajo consigo que estos centros adquiriesen una función defensiva que hasta entonces no había sido tan destacada. En estos momentos de incertidumbre política, la monarquía mantuvo el dominio directo sobre las fortalezas, con la notable excepción de Alcalá. Será tras la caída de Oreja y el desvanecimiento del peligro almorávide cuando comience una auténtica reorganización señorial.

El dominio político de la Transierra madrileña pasaba necesariamente por la formación de una nueva estructura social, es decir, que la única garantía de integración del territorio era la feudalización del mismo ${ }^{55}$. Esta razón impulsó que desde 1140 en adelante la monarquía traspasara sus derechos en buena parte de los castillos a determinados señores ${ }^{56}$. Los beneficiarios de esta política fueron muy diversos: señores eclesiásticos (arzobispo de Toledo, obispo de Segovia), órdenes militares (Santiago, San Juan) o determinados nobles (Gocelmo de Ribas, Fernando Martínez), aunque estos últimos normalmente acabaron cediendo su dominio señorial a otras instituciones. También intervinieron ciertos concejos; Madrid se convirtió en el más importante de la zona, aunque las dimensiones de su Tierra eran muy inferiores a la de los grandes concejos extremaduranos. Parece haber controlado algunos castillos, como Ribas ${ }^{57}$, y sobre todo amplió y transformó su propia cerca. Segovia intervino igualmente, pero su ámbito de actuación quedó circunscrito a las zonas serranas y únicamente controló el castillo de Calatalifa, inscrito en el sexmo segoviano de Casarrubios ${ }^{58}$. Pocos fueron los recintos fortificados que quedaron fuera del proceso señorializador. Sólo Buitrago y Uceda se mantuvieron durante este período en el realengo ${ }^{59}$,

55 Mínguez, J.M. ${ }^{a}$, Las sociedades feudales, 1. Antecedentes, formación y expansión (siglos $\mathrm{V}$ al XIII), Madrid, 1994, pp. 224-225.

56 Vid. PAstor, R. et alii, «Poblamiento, frontera y estructura agraria en Castilla la Nueva (1085-1230)», Cuadernos de Historia de España, XLVII-XLVIII, 1968, pp. 180-184.

57 Gonzalez, J., Repoblación, vol. I, p. 125; PRCT, doc. 20 (1154.07.11); FITA, F., «Madrid en el siglo XII», doc. 7 (1154.08); AVIII, doc. 705 (1201.06.10).

58 El castillo de Calatalifa había sido donado por Alfonso VIl a la iglesia de Segovia en 1136 , pero en 1161 Alfonso VIII lo entrega al concejo segoviano, cediendo al prelado una cuarta parte de las rentas en la ciudad de Segovia. DCMS, docs. 21 y 62.

59 Aunque Uceda fue donada por la reina doña Urraca a don Fernando García de Hita en 1119 (OMS, doc. 3), su cesión no supuso una señorialización ya que permanece en manos de la mo- 
Castillos, poder feudal y reorganización espacial en la Transierra madrileña...

además del caso ya señalado de Madrid. Estos lugares generaron pequeños concejos realengos, que articularon feudalmente el territorio. La dinámica de relaciones vasalláticas que se generaba con esta política de cesiones permitía la consolidación del dominio castellano en la zona. Pero también la implantación señorial, que en muchos casos se realizó mediante la llegada de elites foráneas, conllevó una serie de cambios en las relaciones sociales de producción, alterando el anterior equilibrio para crear uno nuevo.

Donaciones regias de castillos (ss. XII-XIII)

\begin{tabular}{llcl}
\hline \multicolumn{1}{c}{ Castillo } & \multicolumn{1}{c}{ Beneficiario } & Año & \multicolumn{1}{c}{ Referencia } \\
\hline Uceda & Fernando García de Hita & 1119 & OMS, doc. 3 \\
Alcalá la Vieja & Arzobispo de Toledo & 1125 & PRCT, doc. 10 \\
Calatalifa & Obispo Segovia/Gocelmo de Ribas & 1136 & DMCS, doc. 21 \\
Olmos & Orden de San Juan & 1144 & SJ, doc. 51 \\
Cervera & Obispo de Segovia & 1150 & DMCS, doc. 46 \\
Alboer & Conde Ponce & 1153 & OMS, doc. 19 \\
Ribas & Arzobispo de Toledo & 1154 & PRCT, doc. 20 \\
Oreja & Orden de Santiago & 1171 & OMS, doc. 47 \\
Alarilla & Orden de Santiago & 1172 & OMS, doc. 52 \\
Paracuellos & Fernando Martínez & 1175 & OMS, doc. 74 \\
Talamanca & Arzobispo de Toledo & 1188 & AVIII, doc. 490 \\
\hline
\end{tabular}

Estas transformaciones trajeron consigo la formación del castillo feudal que era representación del poder, centro de captación de rentas y eje de la organización del poblamiento y de la actividad productiva y, en algunas ocasiones, también de la articulación política ${ }^{60}$. Apenas se construyeron nuevas fortificaciones durante este período ${ }^{61}$, por lo que normalmente se reaprovecharon las estructuras preexistentes. Pero éstas habían surgido en un contexto social absolutamente diferente, el musulmán, de base tributaria y segmentaria, por lo que los castillos debieron readaptarse. Internamente se observan cambios generalizados:

narquía, como lo demuestran ciertos documentos sobre excusatos y molinos a principios del XIII (AVIII, docs. 764 y 776) y el propio fuero de Uceda, concedido por Fernando III en 1222 (FITA, F., "Fueros de las villas de Uceda, Madrid y Alcalá de Henares», BRAH, IX, 1886, pp. 230-232.

oo Bazzana, A., Cressier, P. y Guichard, P., Les chãteaux ruraux, p. 165 Barceló, M., «Feudalismo e historia medieval», en BARCELÓ, M. et alii, Arqueología medieval. En las afueras del «medievalismo», Barcelona, 1988, p. 28.

61 Únicamente aparecen como nuevas fortificaciones Navas del Rey, que en realidad es poco más que un torreón de reducidas dimensiones, Perales de Tajuña y quizás, aunque son bastante dudosos y desde luego tardíos (siglo xIII), Fuentidueña del Tajo y Santorcaz, así como la pequeña atalaya de El Torreón de Torritón, en Torremocha del Jarama. Vid. SAEZ LARA, F., «Catálogo», pp. $162-169,198,208,218-220$ y $242-243$. 
pérdida de funciones del albácar, formación de recintos señoriales específicos y abandono de buena parte de las funciones de hábitat ${ }^{62}$, que, o bien se desplazaron a lugares cercanos (Uceda) o simplemente fueron desapareciendo desde finales del XII ${ }^{63}$. No obstante, hubo situaciones diferentes, sobre todo en aquellos lugares que consiguieron convertirse en concejos. Así, en Madrid se mantuvo una cerca urbana, más amplia que la musulmana, mientras el antiguo alcázar musulmán se convertía en una residencia señorial en manos de los tenentes regios de la ciudad ${ }^{64}$. En Talamanca, las murallas se conservaron defendiendo el pequeño entramado urbano, sin que se pueda hablar de la construcción de un bastión señorial, ya que jamás alcanzó una importancia que lo hiciera necesario ${ }^{65}$. En cualquier caso, sobre la base del primitivo hișn se fue levantando una nueva construcción adaptada a la nueva estructura social.

El castillo controlaba generalmente un territorio que, al menos en un primer momento, se presenta homogéneo desde el punto de vista señorial. Los hușūn también debieron poseer un espacio bajo su control, pero éste no se basaba en el "dominio señorial» ni debía estar perfectamente delimitado, como ocurre en los siglos XII y XIII. Así, en 1139, al poco de ser conquistada, Oreja recibe un fuero regio, a fin de consolidar el dominio cristiano, en el que se señalan con precisión sus términos ${ }^{66}$. Quizás la base de estos territorios estuviera en el período musulmán, pero, cambiaron su contenido y dimensiones, llegándose incluso a crear algunos de nuevo cuño ${ }^{67}$, como sucedió en Alarilla (Fuentidueña del Tajo), cuyo te-

62 Guichard, P., «El problema», pp. 125-127; Bazzana, A., Chessier, P. y Guichard, P., Les châteaux ruraux, p. 30; GLıck, T.F., From muslim fortress, pp. 150-151.

63 Esta reducción del tamaño y de las funciones es palpable en los castillos situados en la cuenca del Tajo, como Oreja y Alboer, aunque los restos que quedan son escasos y mayoritariamente bajomedievales. No obstante, la población se mantuvo en Oreja durante este período, como lo demuestra la existencia de tumbas excavadas en roca de tipo bañera. Vid. LARRÉN IZQUIERDO, $H$. «Apuntes»y «El castillo de Oreja (Toledo)».

64 Caballero Zoreda, L. et alii, "Las murallas de Madrid», pp. 9-182; Sáez Lara, F., «Catálogo», pp. 170-181.

65 SÁez LARA, F., «Catálogo», pp. 22,3-227.

66 OMS, doc. 9: "Terminos preterea castello Aurelie tales habere concedo: videlicet ab eo loco ubi Saramba descendit in Tago usque ad Fonticulam et inde ad Ocaniolam, inde vero ad Ocaniam maiorem et inde a Noblelas, inde vero ad ambas Noblelas, et inde ad Alharella, inde vero ad montem de Alcarrias quomodo descendit Taiunia in Saramba"

67 En la zona sur de Portugal se observa una situación parecida, con castillos de origen musulmán que articulan territorios, los cuales inicialmente debieron responder a la antigua articulación espacial, pero no resistieron la reorganización fomentada por los cristianos. BosSELLIER, S., Naissance d'une identité portugaise. La vie rurale entre Tage et Guadiana de I'slam a la Reconquête ( $X^{e}$-XIe siècles), Lisboa, 1999, pp. 136-137. 


\section{MAPA 2. CASTILLOS (SIGLOS XII-XIII)}

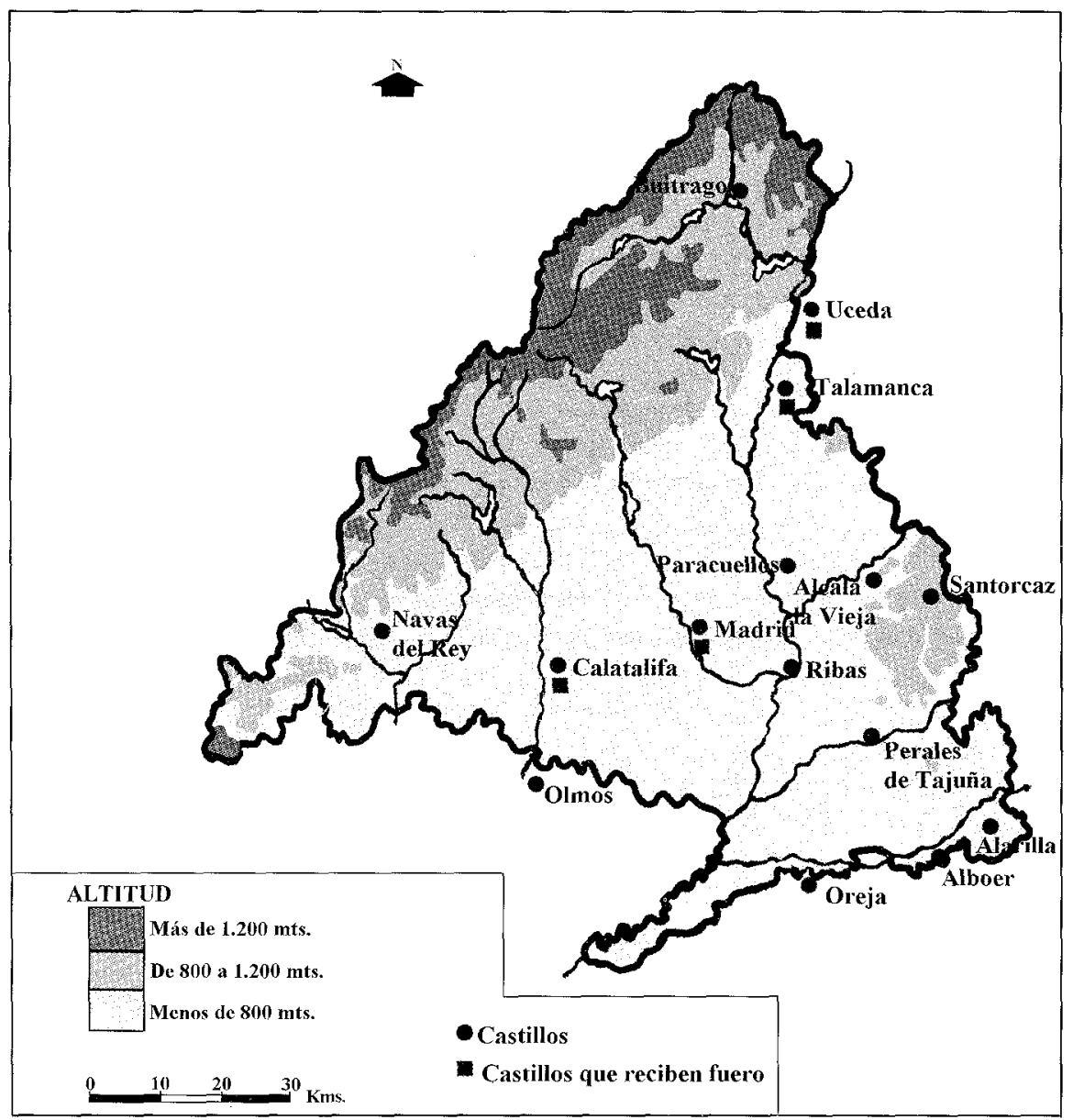

rritorio se creó a partir de los de Oreja, Almoguera (Guadalajara) y Zorita (Guadalajara) ${ }^{68}$.

De todas formas, la definición de los territorios fue menos estable en las zonas serranas, donde no se detectan hușūn, provocando conflictos

68 OMS, doc. 57 (1172-82), donde se señala que Alfonso VII «pobló Alfariella et cepit de termino de Aurelia et de Almoguera et de "Corita et dedit proprium terminum Alfariella». 
por su control ${ }^{69}$. Esta situación se repite en las zonas en torno al Jarama que componen el sur de la Tierra de Madrid y el sexmo segoviano de Valdemoro, donde también fue necesaria la intervención regia para delimitar el espacio ${ }^{70}$. Por tanto, la posesión de derechos sobre un castillo equivalía al disfrute de los mismos sobre un espacio, donde se ejercía un dominio señorial, destacando el papel de recolector de rentas ${ }^{71}$. Esta función se fortalecía ante la ausencia de competencia señorial en los espacios controlados por los castillos, por lo que éstos se convertían, al menos en la antigua zona de hușūn, en los puntos clave para la señorialización y la colonización de las tierras. Las funciones de tipo defensivo no se perdieron, como lo demuestra la resistencia ofrecida a los ataques almohades ${ }^{72}$, pero es indudable que su peso es menor y se concentra en los principales puntos de poder político de la zona, es decir, en Madrid. De todos modos, el mantenimiento de estas funciones repercutió en que se otorgaran los derechos sobre los castillos a determinados miembros de la aristocracia, muy especialmente a las órdenes militares, que controlaron los castillos de la zona sur, que componían una primera línea defensiva (Olmos, Oreja, Alboer y Alarilla). Pero el resultado final fue la formación de encomiendas, es decir, de estructuras señoriales, alejadas del contenido meramente defensivo.

Por tanto, el control de los castillos aseguraba la posesión de derechos señoriales sobre un territorio, creando «nichos señoriales». La «repoblación», que no fue otra cosa que la colonización feudal del territorio, se realizó en la Transierra madrileña siguiendo un modelo aplicado a otras zonas en este mismo período, es decir, la cesión de derechos a los señores y la existencia de una gran propiedad feudal ${ }^{73}$. Así surgen distintos «nichos señoriales» a partir del dominio de un castillo, que pueden ser concejos de realengo (Madrid, Uceda), señoríos eclesiásticos (Talamanca,

69 El más conocido es el largo pleito por la posesión del Real del Manzanares, sobre el que se tratará más adelante. También surgen problemas, posiblemente con la intervención indirecta del concejo abulense, en el valle del Alberche entre la villa de Escalona y su aldea de Cadalso de los Vidrios; MaLALANA UREÑA, A., Escalona medieval (1083-1400), Madrid, 1987, pp. 34-35 y 118-123.

70 FIII, docs. 557 (1235.08.13) y 649 (1239.06.20).

71 Tal papel es evidente en el castillo de Olmos cuando la orden de San Juan acuerda con los vecinos de Illescas (Toledo) que den a dicho castillo "en aloxor cada año, de cada quartejón II fanegas, una de trigo e otra de cevada...e este aloxor deven ellos traer a su costa al castillo de Olmos, el día de sant Estevan»; SJ, doc. 288 (1243.05).

72 Anales Toledanos, pp. 163-164

73 González, J., Repoblación, vol. II, p. 170 y ss.; Molénat, J.P., Campagnes, pp. 77-79; LALiENA CORBERA, C., «Expansión territorial, ruptura social y desarrollo de la sociedad feudal en el valle del Ebro, 1080-1120», en Laliena Corbera, C. y Utrilla Utrilla, J.F. (eds.), De Toledo at Huesca, pp. 208 y ss.; LARREA, J.J., La Navarre. 
Alcalá) o encomiendas (Oreja, Olmos, Paracuellos). Algunos de estos lugares recibieron fuero por parte del rey o de sus señores. La concesión foral representaba un apoyo a la jerarquía del castillo sobre el territorio, reconociendo la persistencia de la función habitacional. Posteriormente los señores mantuvieron estos derechos e incluso pudieron dar otros nuevos, fortaleciendo el «punto central» de su dominio aunque la dinámica posterior favoreció el auge de nuevos lugares. A pesar de la tendencia a generar espacios homogéneos en el plano señorial, es también cierto que aparecen ciertas anomalías, es decir, nuevos señores dentro de dichos territorios ${ }^{74}$. Esto es mucho más evidente en las zonas donde el modelo de hüșun había sido menos fuerte y, por consiguiente, la delimitación de los ámbitos señoriales fue mucho más compleja ${ }^{75}$.

Mediante este dominio se produjo el proceso de colonización del espacio, llevado a cabo por pobladores cristianos, si bien no cabe desestimar la posibilidad de que hubieran permanecido ciertos grupos marginales de origen musulmán o mozárabe. En cualquier caso, la mayor parte de los habitantes autóctonos debieron abandonar las tierras e irse hacia otras zonas de al-Andalus ${ }^{76}$. Se hizo necesaria la adaptación de los procesos de trabajo campesinos a las nuevas exigencias de los señores, dando lugar a cambios en los cultivos y en el diseño de los espacios. Este proceso es fundamental a la hora de comprender la nueva estructura socio-económica, pero su estudio no puede abordarse aquí en profundidad. Se observa en general la formación de cultivos de secano, especialmente cerealísticos, en la mayor parte de la zona sedimentaria, manteniéndose, en cambio, la ganadería en la Sierra. Sin embargo, esta actividad se halla ahora en manos de poderosos señores, en especial del concejo de Segovia estableciéndose rutas de trashumancia y un control por parte de los grupos dominantes. El cereal se convierte en el producto principal, cultivado en un régimen de pequeña propiedad por familias nucleares, supeditadas a los

74 Un caso puede ser la pertenencia de Cervera al obispo segoviano primero y al palentino después; DCMS, docs. 46 (1150.12.13), 81 (1190.03.16) y 83 (1190.03.17). Otro ejemplo es la concesión de Valnegral y Villanueva del Jarama a Santo Domingo de Silos en 1083, y la formación del burgo de San Martín, en Madrid, por parte de dicha abadía en 1126, todo ello en los términos del concejo madrileño; Vivancos Gomez, M.C., Documentación del monasterio de Santo Domingo de Silos (954-1254), Burgos, 1988, docs. 20 y 42.

75 Así sucede en el Tajuña bajo, donde aparecen, dentro de un espacio propio del concejo segoviano, bienes del obispo de Segovia y de la orden de San Juan; DMCS, docs. 45 (1150.02.12) y $136(1240.12 .28)$ y $S J$, doc. 100 (1168.03).

76 Este vacio demográfico dificultará las labores de colonización, que no se acelerarán hasta el siglo XIII. GRAÑEDA MIÑ́N, P. et alii, "La minería medieval al sur del Sistema Central: Madrid y su entorno", en I Jornadas sobre Minería y Tecnología en la Edad Media peninsular, Madrid, 1996, p. 254. 
derechos señoriales sobre la tierra que generan el pago de la renta ${ }^{77}$. Las aldeas cristianas definen, en consecuencia, sus límites con precisión, para saber quiénes cultivan qué solares y a qué señor pertenecen ${ }^{78}$. Al mismo tiempo, se producirá una tendencia hacia la concentración de los asentamientos, lo que da lugar a la desaparición de antiguas alquerías y a la formación de nuevos núcleos ${ }^{79}$. De todos modos, el hecho de que exista una cierta homogeneidad señorial permitirá que aldeas enteras pertenezcan a un único señor, facilitando así su dominio, pero se necesita entonces delimitar los términos con otras aldeas vecinas. Las zonas de regadío en las vegas de los ríos también se ven considerablemente alteradas. Los molinos en las riberas del Jarama bajo, del Tajuña o del Tajo se encuentran en manos señoriales, que convierten un antiguo elemento de utilización comunitaria en un instrumento de captación de rentas, modificando su articulación interna ${ }^{80}$.

La formación de «nichos señoriales» a través del control de castillos es una característica común pero con un resultado no siempre idéntico. La dinámica feudal implanta una serie de diferencias entre los distintos castillos y no todos son equivalentes. En la cúspide se encuentran centros urbanos, como Madrid, auténtico eje regional que se constituye como "comunidad de Villa y Tierra» en el siglo XIII ${ }^{81}$. Este concejo de realengo no posee unas dimensiones similares a los grandes centros de la Extremadura cas-

77 Sirvan como ejemplo los censos que han de pagar los campesinos de Humanes de Madrid en 1173 a Pelayo Pérez de Frómista: «ut in unoquoque anno yugo bovum dent mihi unum cafiz de cevera, medietatem ordecei et medietatem tritici. Alii vero qui non arant dent mihi $1 / l^{\circ}$ fanegas de cevera, medietatem tritici et medietatem ordeceis (SJ, doc. 110). Esta aldea pasará poco después a ser controlada por el comendador sanjuanista de Olmos. Vid. BARQuero Goñl, C., «La organización social del espacio entre Madrid y Toledo: el ejemplo de Humanes de Madrid durante los siglos XII y XIII», en Segura Graíno, C. (ed.), Orígenes históricos, pp. 75-90.

78 Aunque el origen de la aldea cristiana haya sido una qarya, como reflejaria la toponimia, el nuevo asentamiento posee funciones nuevas y una articulación con el espacio diferente. Vid. MolÉnAT, J.P., Campagnes, pp. 111-117; Bossellier, S., Naissance, pp. 146-149.

79 Un caso de desaparición es el de "Las Fuentecillas" (San Fernando de Henares), que sería una alquería musulmana, que deja de habitarse en el siglo XII; BERMEJo CRESPO, J.L. y MuÑoz LóPEZ-AstiLleros, K., «Una explotación agrícola». Por el contrario, el poblamiento disperso en el denominado valle de Salvanés da lugar en el siglo XIII a la formación de Villarejo de Salvanés; SAÉz LARA, F., «Catálogo», p. 254.

Bo En la concesión de! castillo de Alboer al conde don Ponce se señala ya que se dona "cum fluviis et molendinis»; OMS, doc. 19 (1153.11.18). También se habla de una «zuda» que se encontraba "sub muro istius castelli de Alfarella" y que es cedida a San Vicente de Toledo; OMS, doc. 33 (1167.01.19). Los molinos eran ya un instrumento claramente señorial en el xill, cuando don Sancho, arcipreste de Sepúlveda, funda dos capellanías en la iglesia de Segovia dotándolas con casas en Morata de Tajuña y molinos en el río Tajuña; DCMS, doc. 136 (1240.12.28).

${ }_{81}$ GiberT, R., El concejo de Madrid. Su organización en los siglos XII al XV, Madrid, 1949; Romero FERnÁndez-PACHECo, J.R., «Madrid, 1086-1500. Notas sobre el espacio, su organización y" ocupación», en Segura Graiño, C. (ed.), Orígenes históricos, pp. 41-60. 
tellano-leonesa, pero se ajusta mejor a los concejos que se crean en el reino de Toledo, hecha la excepción de Toledo y Cuenca. Surge una elite concejil muy vinculada a la monarquía, al tiempo que existe un auge comercial, palpable ya en el xili. El primitivo recinto musulmán será ampliado con una muralla que es ya una fortificación de la villa. El otro núcleo urbano de época musulmana, Talamanca, no tendrá un desarrollo semejante, aunque mantendrá hasta bien entrado el siglo XIII una cierta preponderancia, que le permitirá crear un territorio propio. Por otro lado, la mayor parte de los castillos ejercen de centros de poder rural, cuyo ámbito de influencia se extiende por un territorio próximo donde se configura un poder señorial recibiendo además concesiones forales. Por último, determinados centros, que en realidad debían ser pequeños puntos defensivos, tendrán un protagonismo menor. Aunque inicialmente formaron núcleos de poder señorial (Alarilla, Alboer, Ribas), su decadencia es temprana. Hacia finales del XII debieron perder toda su funcionalidad ${ }^{82}$. Esto se debería a que las transformaciones de la feudalización rompieron el esquema social en el que se basaban (caso de Ribas) o porque simplemente eran centros defensivos desprovistos de un control efectivo del territorio, como sucede con Alarilla, cuyo término es creado «ex novo» y del que carecía en época musulmana.

Las razones de esta jerarquización son variadas. No se debe desdeñar la herencia musulmana, ya que todos los hușūn no pertenecían a una categoría uniforme. No obstante, es la propia dinámica feudal la que establece esa división. Por un lado, hay que tener en cuenta los intereses señoriales, que pudieron privilegiar ciertos centros sobre otros, como debió suceder con Alarilla y Alboer respecto a Oreja. Tampoco es posible olvidar la distinta fuerza de los señores; los nobles que recibieron castillos no consolidaron posteriormente su dominio, mientras que las órdenes militares y los señores eclesiásticos, en especial el arzobispo de Toledo, más fuertes, fueron capaces de llevar adelante esa iniciativa, como pone de manifiesto la encomienda de Paracuellos, un islote santiaguista. En esta circunstancia participa el interés de la monarquía por fortalecer determinadas instituciones que garanticen la articulación de la región en la Corona de Castilla y también la predilección de los magnates por consolidar sus dominios en áreas más seguras y mejor colonizadas. Por otra parte, el poder monárquico apoyó la existencia de un concejo de realengo en Madrid, al que defendió de la expansión segoviana, pero también de la

82 Por ejemplo, Ribas aparece en 1201 simplemente como «aldea de Magerito"; AVIII, doc. 705. 
formación de núcleos señoriales en su interior, situación que pervivió en la Baja Edad Media.

La evolución de las zonas serranas difiere de cuanto sucede en la cuenca sedimentaria, ya que no se parte del modelo de hușūn, sino de una ocupación del espacio a través de ciertos asentamientos en altura y una red poco consolidada de pequeños núcleos con una base ganadera en un ámbito que no controlaba el poder andalusí de manera directa. Esta situación de partida trae consigo que no exista una red de castillos feudales en los siglos XII y XIII similar a la de la cuenca sedimentaria. Es cierto que durante este período se debió realizar la fortificación de Buitrago de Lozoya, con el objetivo de conformar un centro que controlara el paso ganadero. Es muy posible que hubiera una infraestructura previa, lo que motivó la «repoblación» del lugar y la organización de una suerte de pequeño concejo de montaña que integraba básicamente el valle que rodea dicha localidad ${ }^{83}$. Pero constituye prácticamente la excepción, ya que sólo se pueden documentar otros dos recintos en la zona. Uno de ellos es Calatalifa, dentro del sexmo de Casarrubios, donado al concejo segoviano. Muy probablemente se trata de un añadido al primitivo dominio sobre el área por parte de Segovia, cuyas miras estaban en la zona ganadera y no en este espacio sedimentario. Por otra parte, el castillo de Navas del Rey es un pequeño torreón que apenas ejerció labor alguna de jerarquización socio-espacial.

El tipo de hábitat cambió sustancialmente. Los asentamientos en altura fueron abandonados mientras se generaron otros en las zonas más llanas, como se pone de relieve en Cadalso de los Vidrios ${ }^{84}$. La desaparición de estos núcleos se engloba en el proceso de subordinación de las comunidades autóctonas, que habían segregado estos lugares con funciones de control del territorio, pero dentro de sus limitadas capacidades. La llegada de los nuevos señores trastocó este modelo, ya que los centros de dirección se encontraban fuera del espacio regional y las prácticas ganaderas se englobaban en recorridos trashumantes entre una y otra zona de la cordillera. El abandono de estos lugares no alteró la existencia de un hábitat disperso y poco estable, muy relacionado con la ganadería y con

3 González, J., Repoblación, vol. I, pp. 299-300.

84 El asentamiento de Peña Muñana se abandona, pero en los siglos XII y XIII se ocupan zonas de llanura, como se documenta en la necrópolis de "La Mezquita»; BENITO LóPEZ, J.E. et alii, "Aportación al estudio de las necrópolis medievales en la meseta: «La Mezquita" (Cadalso de los Vidrios, Madrid)", en / Congreso de Arqueología Peninsular, vol. IV, pp. 561-566. Un caso muy similar es el "Cancho del Confesionario" con la formación de los núcleos de Manzanares; FIII, doc. $767(1248.09 .24)$. 
una baja demografía. Es muy probable que durante todo el siglo XII no hubiera una colonización por parte de los señores feudales, pero ésta se intensificó a partir del segundo tercio del XIII, como se observa en el Real del Manzanares. En cualquier caso, esta colonización competitiva, anterior a las que se han detectado en zonas de la Extremadura castellano-leonesa ${ }^{85}$, no afectó a un modelo de poblamiento en pequeños asentamientos, que perduró durante la Baja Edad Media. El análisis del sexmo de Casarrubios y del Real del Manzanares revela esa tipología de asentamientos, que sólo tardíamente llevarán a la creación de pequeños «lugares centrales» 86 .

La ocupación de este espacio se llevó a cabo por los concejos extremaduranos, especialmente por Segovia. En la zona más septentrional de la región se conoce la intervención del concejo de Sepúlveda en algunos lugares ${ }^{87}$. Pero es el concejo segoviano el que se hace con el mayor número de tierras. Prácticamente controla toda la zona occidental de la Transierra madrileña (sexmos de Valdelozoya y Casarrubios), con un entrante en las zonas meridionales del sexmo de Valdemoro, que ya se encuentran en el área sedimentaria. En cuanto al Real del Manzanares, su disputa con el concejo de Madrid abarcó todo el siglo XIII, como consecuencia de los intereses contrapuestos de ambas instituciones ${ }^{88}$. Aunque en 1152 Alfonso VII donó este espacio a Madrid, no lo hizo expresamente ${ }^{89}$. Segovia era un concejo más fuerte y debía estar actuando sobre el terreno, a lo que se añadía la debilidad de su rival. La expansión sobre este territorio era lógica, ya que respondía a los intereses ganaderos de

85 Barrios García, Á, «Poder y espacio social: reajustes del poblamiento y reordenación del espacio extremadurano en los siglos XIII-XV», en Despoblación y colonización del valle del Duero, siglos VII-XX. IV Congreso de Estudios Medievales, León, 1995, pp. 235-244.

86 Martínez Moro, J., La Tierra en la comunidad de Segovia. Un proyecto señorial urbano (1088-1500), Valladolid, 1985, pp. 68-74; CARRAsco TezAnOS, A., «Estructura y articulación social del poblamiento en la Sierra de Madrid en el siglo Xv: el Real del Manzanares y los sexmos de Casarrubios y Lozoya», en Segura Graíñ, C. (ed.), Orígenes históricos, pp. 91-109.

87 Así, en 1300 la villa de El Berrueco y los pueblos de Cardoso, El Vado y Colmenar de Sepúlveda pasan al concejo de Sepúlveda, aunque los tres pueblos volverán al mayorazgo de los Mendoza; Lombana Domínguez, N., «El enclave», pp. 118-119. En 1305 el concejo de Sepúlveda exime del pago de derechos a todos los que vivan o vayan a morar los lugares de Roblegordo, Colladillo y Somosierra; SÁEz, E., Colección diplomática de Sepúlveda, Segovia, 1956, doc. 15.

88 Vid. Tormo, E., «El estrecho cerco del Madrid de la Edad Media por la admirable colonización segoviana", BRAH, CXCVIII, 1946, pp. 47-205; GonZÁLEZ, J., Repoblación, vol. I, pp. 301307; PASTOR, R., «Apuntes para el estudio de los conflictos por el espacio ganadero del concejo de Madrid en el siglo XIII», en / Jornadas de estudios sobre la provincia de Madrid, Madrid, 1979, pp. 678-683; Martínez Moro, J., La Tierra, pp. 18-21; PANAdero ACedo, C., "Los límites del territorio de Madrid (siglos XI-XiII)", en Segura Graíño, C. (ed.), Origenes históricos, pp. 61-74.

69 DOMingo Palacio, T., Documentos del archivo general de la villa de Madrid, Madrid, 1889 , pp. 11-13. 


\section{MAPA 3. ZONAS BAJO CONTROL SEGOVIANO}

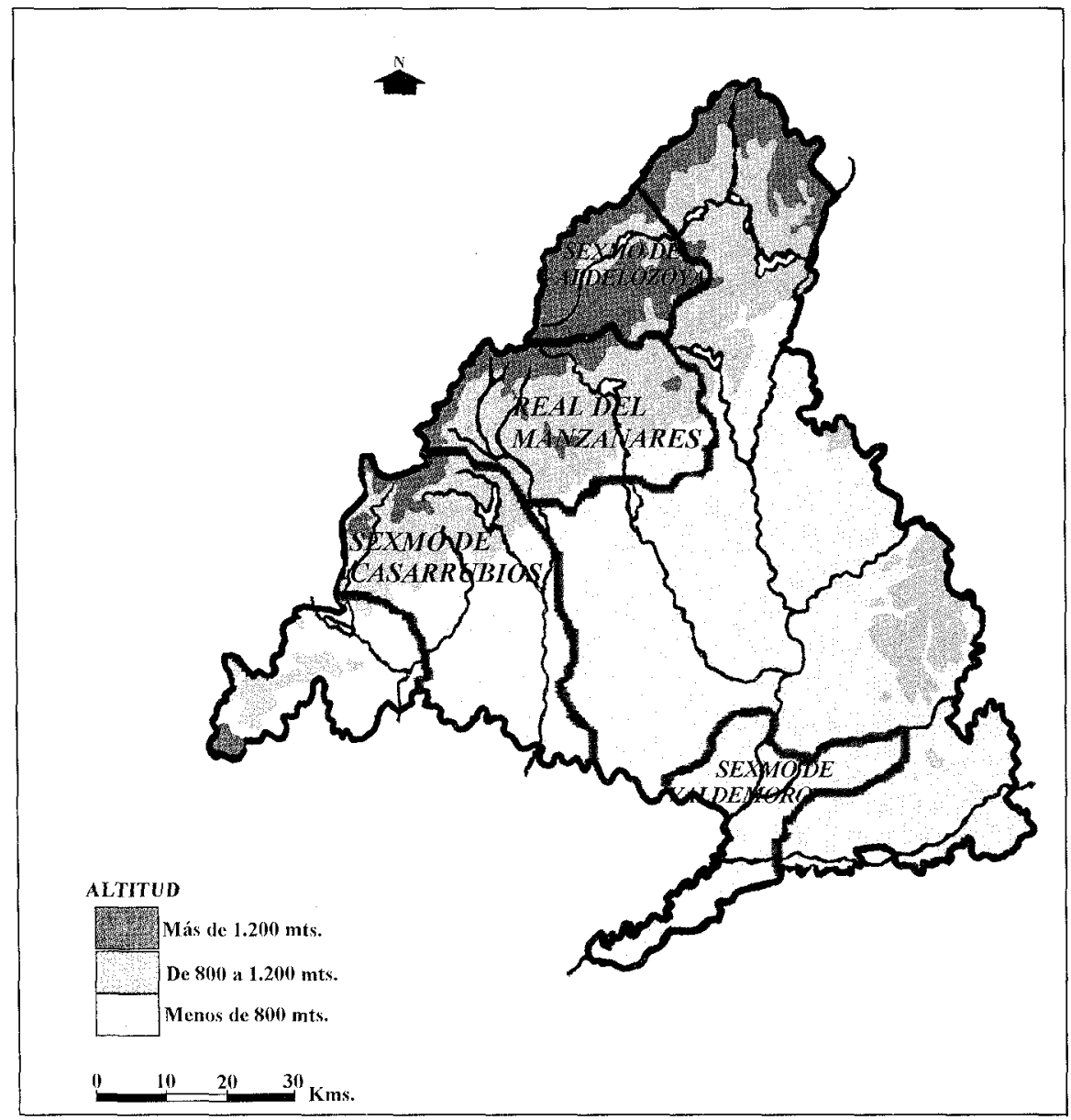

los segovianos y se situaba entre Valdelozoya y Casarrubios. Allí se llevó adelante una política de colonización que, a partir de los asentamientos preexistentes, como se comprueba por la toponimia ${ }^{90}$, buscaba la fijación

90 Frente a la opinión de que estos territorios estaban sin habitantes (GonzÁl.EZ, J., Repoblación, vol. I, p. 300), se observa la persistencia de topónimos de origen árabe como Alpedrete o Galapagar, aunque su escaso número indicaría una débil estructura del hábitat concentrado. De todos modos, el propio interés por el control del Real del Manzanares sería un síntoma de que no estaba yermo. 
Castillos, poder feudal y reorganización espacial en la Transierra madrileña...

de núcleos y la puesta en cultivo de las tierras ${ }^{91}$. La confrontación con Madrid no se hizo esperar ya que los madrileños acudieron al rey para quejarse de tal comportamiento, lo que motivó la actuación de éste ${ }^{92}$. Durante la segunda mitad del XIII, el Real del Manzanares se mantuvo bajo el dominio directo del rey, con usufructo segoviano y madrileño, hasta que en el XIV este territorio se señorializó.

La colonización segoviana tiene su continuación en un impulso más amplio y colectivo, como son los quiñones, que abarcaban todos los sexmos ${ }^{93}$. Sin embargo, su actividad sobrepasa los límites temporales que nos hemos marcado. Los quiñoneros también actuaron en el sexmo de Valdemoro, una zona igualmente conflictiva entre los concejos de Segovia y Madrid y la orden de Santiago ${ }^{94}$. Se trata de otra área donde el modelo de husuun no se había desarrollado con fuerza; es la zona del Jarama bajo y su confluencia con los ríos Tajuña y Tajo. Un área de potencialidad agraria, muy vinculada a las vegas de los ríos, donde las comunidades andalusies no habían segregado castillos. Es posible que su dominio por parte de Segovia provenga de la indefinición de este espacio, que no se relacionaba directamente con ninguna fortaleza, por lo que no se pudo seguir la política de formación de «nichos señoriales» homogéneos. Aquí el antiguo hábitat disperso de las alquerías se fue concentrando en determinados lugares, en especial en el actual núcleo de Valdemoro.

La colonización segoviana buscaba la señorialización, en nombre del concejo, de todas las tierras que estaban bajo su influencia. Es destacable el predominio de las áreas de potencialidad ganadera, que se relacionan con los intereses de las elites concejiles de los lugares de la Extremadura castellano-leonesa. Muy probablemente la influencia de Segovia proceda de antes de la conquista y la posesión de estos territorios se fundamente en su capacidad para controlar estas áreas que actuaban al margen del poder central andalusí. No recibió para ello título alguno, sino que simplemente se incorporaron a su área de influencia, transformándose en el siglo XIII en sexmos de su Tierra. Su protagonismo militar durante el siglo XII, cuando las milicias segovianas conformaban uno de los principales com-

91 Así, en 1249, tras la intervención inicial de Fernando III contra los segovianos, éstos, según dice el concejo de Madrid, habían recomenzado su actividad, que incluye formar ciertas pueblas "e pusieron vinnas e árboles, e que labraron en aquellos lugares que yo mandé derribar"; Flll, doc. 784.

FIII, doc. 767 (1248.09.24) y 784 (1249.08.24).

33 Asenjo GonzÁlez, M.a "Los quiñoneros de Segovia (siglos X|V-XV)», en En la España Medieval. Estudios en memoria del profesor D. Salvador de Moxó, Madrid, 1982, vol. II, pp. 57-82.

${ }_{94}$ Los oficiales regios tuvieron que delimitar esta zona en 1208; AVIII, docs. 828, 829 y 830. 
ponentes del ejército castellano, permitió que la situación se consolidase ${ }^{95} \mathrm{e}$ incluso hubo una donación de aldeas en la Tierra de Alcalá, que no fructificó ${ }^{96}$. Los intereses de Segovia estaban en ese espacio ganadero y en su disfrute, para lo cual no recurrieron a la formación de castillos, ya que el principal castillo no era otro que la propia villa castellana.

Por tanto, las zonas donde no se había llevado a cabo la implantación de hușūn tuvieron una evolución distinta que afectó al papel de los castillos. También el curso del Alberche se encuentra dentro de esta dinámica. Hasta la formación del monasterio de Valdeiglesias en el siglo XIII, que concentró parte del poblamiento y creo una instancia señorial local propia no asentada en un castillo sino en un centro religioso ${ }^{97}$, el área estuvo en manos del concejo de Escalona. El principal escollo fue el control de Cadalso de los Vidrios, entendido no como la actual localidad, sino como todo el pequeño tramo de valle en torno a ella. En Cadalso tiene bienes la orden de San Juan ${ }^{98}$ y el límite con el concejo abulense se trazaba en sus inmediaciones ${ }^{99}$. La formación de una aldea concentrada, proceso que se inicia en el siglo XII y cristaliza en el XIII, favoreció el crecimiento agrario de un centro relativamente alejado de Escalona, cuya fuerza era muy inferior al poderoso concejo de Ávila. Quizás bajo la instigación de éste, Cadalso de los Vidrios buscó segregarse de Escalona, aunque no consiguió su objetivo hasta la Baja Edad Media ${ }^{100}$. De cualquier forma, el poblamiento aquí es similar al de los sexmos segovianos, con una fuerte presencia ganadera, escasa presencia de poblamiento árabe, hábitats dispersos que se concentran hacia el siglo XIII y un predominio de los topónimos romances ${ }^{101}$.

El modelo de dominio señorial a través del control de los castillos no es uniforme en el espacio de la Transierra madrileña, pero tampoco constituye un elemento inmóvil. Durante el siglo XIII, en las zonas serranas, se aprecia un movimiento de colonización, que se apoya en la formación de

95 Vid. ASENJo GonzÁLEZ, M. a «Sociedad urbana y repoblación de las tierras de Segovia al sur de la sierra de Guadarrama», en En la España Medieval. Estudios en memoria del profesor D. Claudio Sánchez-Albornoz, vol. I, Madrid, 1986, pp. 126-128.

96 AVIII, doc. 547 (1190.03.25).

97 Sáez Lara, F., «Catálogo», p. 210.

98 SJ, docs. $164(1188.09 .19)$ y $347(1272.05 .08)$.

99 AVIII, doc. 365 (1181.04.21): «...usque ad capud de Buena, et inde ad Cadafalsso...».

100 Malalana Ureña, A., Escalona, pp. 118-122; BN, mss. 13.094, f. 134 (1232) y $R A H$, Colección Salazar, M-142, f. 122 (1233).

101 Pérez López, M. y López Rodriguez, P., «Análisis topónimico-arqueológico de contexto medieval en el sector SO. de la Comunidad Autónoma de Madrid. El valle del Alberche. Primera aproximación", en I/ Congreso de Arqueología Peninsular, vol. IV, pp. 567-576. 
núcleos más concentrados y en la puesta en explotación de determinadas zonas (muy evidente en el caso de los quiñones segovianos), buscando un aumento de los ingresos fiscales que proviene del ejercicio de la jurisdicción sobre esta área por parte de los concejos, que complementa los intereses de tipo ganadero, los cuales se mantuvieron presentes durante todo este período. De igual manera, se observa cómo en esta centuria decae el sistema de castillos, muchos de los cuales pierden todas sus funciones. El alejamiento de la frontera en el primer tercio del XIII, con el retroceso generalizado de las posiciones musulmanas, hasta el punto de formarse la nueva frontera en la Andalucía bética, podría explicar este fenómeno ${ }^{102}$. Sin embargo, es una hipótesis que únicamente se justificaría en aquellos castillos que tuvieran una función básicamente militar, circunstancia que, como se ha señalado, no era en absoluto común. Las razones deben encontrarse en la consolidación del sistema feudal en la región.

La creación de espacios agrarios es fundamental. Los asentamientos en altura no son propicios para una agricultura de secano con campos cultivados por pequeñas familias. Es más lógica una localización en aldeas cercanas a los campos, que permiten una fácil comunicación con los mismos, dentro de un mundo rural "enceldado", donde los límites aldeanos se han señalado con precisión, a fin de configurar perfectamente el ámbito de actuación de cada señor. Por tanto, la adecuación a los nuevos cultivos genera una bajada del hábitat, que ya se había fomentado con la consolidación del castillo como residencia eminentemente señorial desde el siglo $\mathrm{XII}^{103}$. No obstante, las excavaciones realizadas muestran cómo hasta principios del XIII ciertos castillos funcionaron como asentamientos ${ }^{104}$.

Por otra parte, el castillo sirvió de base para la creación de un aparato productivo suficientemente consolidado, por lo que era necesario que hubiera un control directo sobre éste. El señor disfrutaba de su "dominio señorial» ${ }^{105}$, es decir de su capacidad para imponer rentas sobre el conjunto del campesinado, gracias a ser el poseedor de los derechos derivados del castillo. Una vez que ha madurado el nuevo sistema de producción,

102 Pastor, R. et alii, «Poblamiento, frontera», p. 191.

103 También en el Aragón posterior a la conquista los asentamientos cristianos tienden a descender, situándose en las pendientes o a los pies de los antiguos hüsun, reconvertidos en castillos señoriales. SÉNAC, P., «Du hisn musulman».

104 Son los casos de Alcálá la Vieja, Calatalifa, Olmos u Oreja, aunque los materiales demuestran un paulatino empobrecimiento. Vid. SÁEZ LARA, F., «Catálogo»; MARTínEZ LILLo, S., «El poblado".

105 Utilizamos aquí los conceptos definidos por ESTEPA DíEZ, C., «Formación y consolidación del feudalismo en Castilla y León», en En torno al feudalismo hispánico. I Congreso de Estudios Medievales, Ávila, 1987, pp. 157-256. 
éste no necesita de un control tan directo, sino que puede funcionar con una cierta autonomía, sin la intervención señorial, haciendo la importante salvedad de la captación de renta, que influye en los procesos de trabajo campesino y los altera. En este sentido, la tendencia es hacia la obtención, por parte de la nobleza, de un «señorío jurisdiccional», donde el factor por el que se obtiene la renta no es el control directo sobre el campesino, sino el ejercicio de la jurisdicción. Esto es muy evidente en los concejos de realengo. El monarca, como señor superior, había creado un instrumento intermedio en el que delegaba su capacidad señorial y parte de la jurisdicción, pero se reservaba un papel superior en dicha jurisdicción, ya que el concejo estaba vinculado a su persona y, dada esa relación, podía exigir ciertas rentas. Otros concejos menores, como Talamanca o Alcalá de Henares se articulaban por el mismo mecanismo, pero era el arzobispo de Toledo el que ejercía el papel de señor de la comunidad, por encima del cual seguía funcionando el rey.

Precisamente el arzobispo de Toledo representa un ejemplo de la concentración señorial. Determinados señores se hicieron con el control de amplias áreas, como sucede también con los concejos de Segovia y Madrid y con la orden de Santiago. Esta situación difiere de la inicial dotación de castillos, en la que los monarcas beneficiaron a numerosos nobles particulares. Desde el último tercio del XII se aprecia la paulatina concentración del poder señorial en muy pocas manos. De esta forma, el castillo perdía buena parte de su centralidad, ya que se integraba en una estructura superior, donde se diluye su papel. Son las opciones de estos señores las que pueden llevar a la desaparición de ciertos castillos o a los cambios de sus funciones. Así, Alarilla se convierte en un punto de gravamen de la actividad comercial que atraviesa el Tajo, gracias al cual la orden de Santiago obtuvo pingües beneficios ${ }^{106}$. La función de control del territorio se pierde y con ella toda funcionalidad del recinto amurallado. En cambio, parece más interesante para el señor el desarrollo de Fuentidueña del Tajo, localidad con unas condiciones más acordes con las nuevas necesidades señoriales. Esta misma orden permitirá también el deterioro de Oreja y Alboer, pero preservará como mero centro señorial el

${ }_{106}$ En el siglo XII existía ya un portazgo que gravaba las mercancías que pasaban el Tajo por Alarilla, enumerándose un amplio elenco de las mismas; OMS, doc. 58 (1172-1182; MARTíN, J.L., «Portazgos de Ocaña y Alarilla», AHDE, XVII, 1962, pp. 519-526. En 1206 Alfonso VIII prohibió el paso del Tajo con mercancias por otros lugares que no fueran Toledo, Alarilla o Zorita, favoreciendo de esta manera la centralidad del puente, pero no de la fortaleza. TORRES BALBÁs, L., «Castillo de Fuentidueña», BRAH, CXL, 1957, pp. 41-43; MaLALANA UREÑA, A., «Puentes-fortaleza en el Tajo: el tramo Zorita de los Canes (Guadalajara)-Castros (Cáceres)", BAM, 4, 1989, pp. $195-222$. 
castillo de Malsobaco (Paracuellos del Jarama), desde el que se articula una pequeña encomienda entre las Tierras de Madrid y de Alcalá. Por tanto, para estos pocos señores, el castillo deja de ser un elemento relevante, que sólo mantiene su funcionalidad en casos muy específicos y como mera residencia señorial.

Todo ello favorece que en el siglo XIII los castillos pierdan su «centralidad", aunque en la Baja Edad Media se producirá un nuevo auge, si bien con otras características. Esta decadencia se plasma en los concejos «encastillados". Varios de los castillos del siglo XII recibieron fueros por parte del rey o de otros señores, configurándose como concejos. Algunos de estos lugares obtendrán posteriormente un fuerte desarrollo. Es el caso de Madrid, cuyo fuero de 1202 se constituyó como el elemento sustentante del desarrollo de la "comunidad de villa y tierra" posterior ${ }^{107}$. Algo más tardío fue el caso de Alcalá de Henares, pero su fuero de 1223, que sustituye al primitivo de 1135, se refiere al burgo de San Justo y no al primitivo hiṣn y buscaba el fortalecimiento del nuevo núcleo ${ }^{108}$. Ambos lugares constituyen sendos éxitos y se conformarán como centros urbanos, uno de los cuales, Madrid, estaba en la órbita del realengo. Su expansión espacial es evidente en el siglo xIII, cuando desborda el primitivo centro musulmán y se crean nuevas instituciones señoriales como el monasterio de Santo Domingo el Real. Existe un apoyo por parte de los señores a estos centros, que se convierten en ejes de importantes jurisdicciones que subsumen otras inferiores. Pero tampoco debe desdeñarse el propio desarrollo interno de los grupos más dinámicos de ambas localidades. En el caso madrileño, la importancia adquirida como centro de vías de comunicación y la participación de sus milicias en las guerras del siglo xIII expresan la importancia creciente de sus elites dominantes. En Alcalá fue primordial el aspecto comercial, que el arzobispo toledano, con el apoyo del rey, no dudó en fortalecer ${ }^{109}$.

Otros concejos pudieron mantener sus posiciones, aunque sin alcanzar el grado de desarrollo de los dos lugares señalados. Buitrago de Lozoya

107 El concejo de Madrid recibió el fuero de Toledo en 1118, pero era un breve fuero que permitió la constitución del concejo. Fue sustituido en 1202 por otro de Alfonso VIII que señala una serie de normas, que se amplió en 1222, sirviendo de base para la formación de la «comunidad de villa y tierra». Segura Graiño, C., «Madrid en la Edad Media», pp. 79-80; FITA, F., «Fueros de las villas», pp. 233-235 Domingo PaLAcio, T., Documentos, pp. 19-63 y 65-69.

108 El texto lleva el expresivo encabezamiento: «Privilegium de foris Sancti Justi apud Alcalam»; FITA, F., «Fueros de las villas», pp. 236-239.

109 Ya en 1184 Alfonso VIIl concedió, a ruegos del arzobispo de Toledo, «feriam singulis annis perpetuo in Sancto Justo de Alcala celebrandam»; PRCT, doc. 31. 
se mantuvo como un pequeño núcleo que articulaba un espacio muy reducido, mientras que Talamanca, que recibe en 1223 su fuero por el arzobispo Rodrigo Jiménez de Rada ${ }^{110}$, conserva buena parte de su «centralidad» por los derechos de paso por el puente que atravesaba el Jarama. En cambio, Calatalifa sufrió una decadencia más fuerte. Los niveles arqueológicos detectan un paulatino abandono, que se acelera en este período. En 1270 el concejo de Segovia había donando a García Martínez, notario del rey, "el viso de Calatalifa» "111; la utilización del nombre «viso» parece dar a entender que se hallaba ya deshabitado. En 1302 aparece como una de las zonas donde se distribuye tierra a los quiñoneros segovianos ${ }^{112}$, lo que induce a pensar en su desaparición como castillo y aún más como «punto central», aunque pueda sobrevivir como una pequeña aldea ${ }^{113}$. Algo parecido sucede con Oreja, cuyo castillo aunque sobrevive en la Baja Edad Media, se ha convertido en una residencia señorial sin influencia sobre el poblamiento y con una importancia dentro del conjunto santiaguista muy inferior a la villa de Fuentidueña del Tajo, que recibe fuero en $1328^{114}$. Estos fracasos ejemplifican las razones de la disminución de peso de los castillos, ya que son tanto las necesidades productivas, que favorecen localizaciones en el Ilano, como las opciones señoriales las que explican dicho proceso.

El proceso de abandono de los castillos fue paulatino. Las funciones de control señorial permitieron que se mantuvieran las estructuras constructivas, adaptadas a un papel muy secundario en la Baja Edad Media. En cuanto a su papel como asentamientos, hubo un fuerte retroceso, que en determinados casos (Alboer, Ribas, Cervera) supuso una rápida pérdida de su función habitacional. En otros casos, hubo una fase intermedia, en la que el castillo se convirtió en una aldea con un número de pobladores similar al de otros núcleos de su entorno (Calatalifa, Oreja), para posteriormente, en la segunda mitad del XIII y en el XIV perder toda su población. De

110 Fita, F., «Madrid desde el año 1228 hasta el 1234», BRAH, VIII, 1886, pp. 417-418.

111 DMCS, doc. 181.

112 AsEnjo GONZÁleZ, M. ${ }^{a}$, «Los quiñoneros», pp. 79-81.

113 De hecho, su localización se perdió en la Edad Moderna y sólo las excavaciones realizadas desde los años 80 han permitido situar el lugar en el término de Villaviciosa de Odón. Su pérdida de centralidad es lógica, ya que el punto señorial principal es Segovia y las características de su asentamiento no se ajustan a las pueblas que, como El Espinar (Segovia), buscaba realizar el concejo.

114 Rivera Garretas, M., La encomienda, el priorato y la villa de Uclés en la Edad Media (1174-1310). Formación de un señorio de la Orden de Santiago, Madrid-Barcelona, 1985, doc. 245: "Sepan quantos esta carta vieren cómo nos don Vasco Rodríguez por la gracia de Dios maestre de la Orden de la Cavallería de Santiago, por fazer bien e merçet al conçio e los omos bonos de Fuente Duenna...". 
todos modos, hubo algunos lugares que sobrevivieron como núcleos de población. Así sucede con Buitrago de Lozoya, Madrid, Talamanca o Uceda. Pero en todos estos casos se produce una adaptación a la reorganización feudal de la Transierra madrileña, ya que se trata de sedes de concejos, de realengo o señorializados, que sirven como articuladores del espacio, es decir, se convierten en entes feudales. No obstante, sufren importantes cambios relacionados con su nuevo contenido social, como se observa en el crecimiento de Madrid como centro urbano o en el desplazamiento del hábitat en Uceda dentro de la propia altura.

En general se aprecia un descenso altitudinal del hábitat, creándose nuevos centros de población en zonas llanas cercanas a los castillos. Es allí donde se van a crear los nuevos asentamientos, mejor adaptados a las necesidades del nuevo sistema social. El apogeo de algunos de estos núcleos los llevará a convertirse en villas aforadas, desde las que el señor ejerce su jurisdicción a través de un órgano interpuesto. Cuando esto sucede, el papel del antiguo castillo es subsidiario, con una tendencia a su abandono. Los casos más claros son los de Alcalá de Henares y Fuentidueña del Tajo.

El núcleo de la actual Alcalá surge del denominado burgo de San Justo, en una zona que posiblemente coincida con el solar de la ciudad tardoantigua de Complutum. Durante el período musulmán se desarrolló el hișn de Qal'at abd-al-Salam o Alcalá la Vieja, situado en un cerro en la orilla oriental del Henares. Quizás pudo permanecer algún tipo de hábitat poco estructurado o ciertas funciones cultuales en la llanura al otro lado del río, debido a la perduración de la tradición religiosa en torno al martirio de los niños santos Justo y Pastor, cuyo sacrificio se supone que se ejecutó en Complutum ${ }^{115}$. Lo cierto es que desde el siglo XII se conoce la presencia de un burgo de San Justo o de Santiuste, en una zona más llana, amparado por el poder señorial del arzobispo de Toledo, y donde hay una intensa actividad comercial. Este núcleo sufre una fuerte expansión durante el siglo XIII, recibiendo un fuero y convirtiéndose de hecho en el principal centro demográfico de la comarca y en el punto concentrador de la jurisdicción señorial, que abarcaba un territorio, anteriormente ligado

115 Vid. Méndez Madariaga, A. y Rascón Marqués, S., "Complutum y el bajo Henares en época visigoda", en II Congreso de Arqueología Medieval Española, Oviedo, 1989, vol. II, pp. 96 102, Torres Balbás, L., "Estudios de arqueología», pp. 163-164; Castillo Oreja, M.A., «Alcalá de Henares, una ciudad medieval en la España cristiana (siglos XIII-XV)", en La ciudad hispánica durante los siglos XIII al XVl, Madrid, 1985, vol. II, pp. 1.060-61. De todas formas la continuidad de una población mozárabe es una hipótesis endeble y, en cualquier caso, sería un pequeño núcleo de tipo religioso. 
a la fortaleza de Alcalá la Vieja ${ }^{116}$. Por el contrario, los pobladores del cerro abandonan el lugar y el castillo se convierte en residencia señorial y símbolo de su poder durante la Baja Edad Media ${ }^{117}$, mientras la nueva urbe se rodea de un recinto amurallado ${ }^{118}$. Es obvio que la nueva localización surgió como un núcleo mejor adaptado a las condiciones agrícolas, cercano a las tierras de secano del norte y al curso del Henares, en su vega más fértil, por el sur. Su auge permitió el desarrollo de actividades comerciales, favorecidas por el paso de una vía que conectaba Zaragoza con las regiones del sur. El arzobispo de Toledo no dudó entonces en favorecer el desarrollo de este lugar a fin de garantizar la obtención de mayores rentas. Una vez consolidado, se procedió a su aforamiento, creando un concejo que servía a sus intereses de señor jurisdiccional.

Fuentidueña del Tajo presenta rasgos similares, aunque su desarrollo como villa nunca alcanzó el grado urbano de Alcalá de Henares. La fortaleza de Alarilla era el castillo más cercano, sito sobre un cerrete de 596 mts. de altitud en la orilla meridional del Tajo. Su importancia como centro señorial se desplazó al control del puente que permitía el paso de mercancías por el río. Fuentidueña aparece como aldea de Alarilla en 1167, cuando Alfonso VIll cedió sus derechos al monasterio de San Vicente de Toledo, cinco años antes de la donación del castillo ${ }^{119}$. Aunque la orden de Santiago se hizo con el control de ambos lugares, es posible que su evolución conjunta se rompiera ya en el XII. Fuentidueña del Tajo fue creciendo durante este período siguiendo el modelo de concentración del poblamiento, que se plasma también en el cercano valle de Salvanés ${ }^{120}$. De nuevo las condiciones son mejores para el aprovechamiento agrario y para la formación de un incipiente mercado. En 1234 Fernando III prohibe las ferias en Fuentidueña del Tajo organizadas por la orden de Santiago, en defensa de los privilegios de otros centros ${ }^{121}$. Este dato demuestra el auge

116 Vid. Castillo Gómez, A., Alcalá de Henares en la Edad Media: territorio, sociedad y administración (1118-1515), Alcalá de Henares, 1989, pp. 118-122.

117 TURINA, A., «El castillo», pp. 190-191.

118 Esto sucedería en 1253; SÁEZ LARA, F., "Catálogo», p. 100.

119 OMS doc. 33: «aldeas Illas querum altera Fons Domine vocatur, altera vero Estremera nuncupantur, cum illa albergeria que est iuxta vadum de Alfarella, cum villariis circumadiacentibus. Sunt etiam iste aldee in termino de Alfarella...».

120 Er 1214 un acuerdo entre el arzobispo de Toledo y el maestre de Santiago fija los derechos sobre las iglesias de Estremera, Fuentidueña y Salvanés (posiblemente Villarejo de Salvanés, ya que se no se menciona como «Val de Salvanés»); RIVERA GARRETAS, M., La encomienda, doc. 72. Parece claro que se está produciendo una concentración del poblamiento, aunque en el caso de Fuentidueña y Estremera debió ser anterior, dado que en 1167 aparecen como aldeas; OMS, doc. 33.

121 Hernandez, F.J., Los cartularios de Toledo. Catálogo documental, Madrid, 1985, doc. 441. 


\section{MAPA 4. DESCENSO ALTITUDINAL DEL HÁBITAT (SIGLO XIII)}
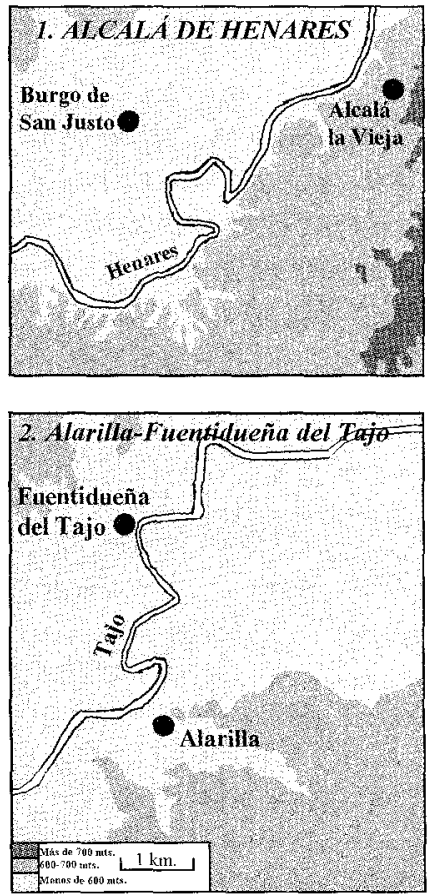

creciente de esta localidad, que se plasma en 1328 cuando recibe estatuto de villa. Sin embargo, el texto habla de eel nuestro castillo de Fuente Duenna" que deberá poblarse ${ }^{122}$. Esta situación ha llevado a considerar la posibilidad de un fenómeno de incastellamento tardío ${ }^{123}$. El hecho de que sea un castillo es accidental, ya que lo que otorga "centralidad señorial» es su papel como villa. Es muy probable que se haya producido ya el abandono de Alarilla, actualmente una ermita, como centro señorial, por lo que la orden de Santiago ha creado otro nuevo centro. Los restos de este castillo muestran claramente que estamos ante un castillo típicamente señorial, donde hay sitio sólo para diez o doce casas, ampliándose el núcleo

122 Rivera Garretas, M., La encomienda, doc. 245: "E porque morades e el nuestro castillo de Fuente Duenna».

123 Molénat, J-P., Campagnes. 
de población a sus pies y sin amurallamiento ${ }^{124}$. La nueva fortaleza de Fuentidueña, cuyo origen quizás esté en el siglo xill es simplemente una residencia señorial y un símbolo de su poder, no un asentamiento, y funciona según las pautas de otros castillos de la época, siendo más importante la organización de la villa ${ }^{125}$.

Por tanto, el papel de los castillos en la Transierra madrileña durante los siglos XII y XIII es muy variado. En primer lugar, hay una zona, el territorio serrano, donde no se registran apenas castillos, a excepción de Buitrago de Lozoya, en la que el poblamiento "encaramado" desaparece, frente a lo que sucede en la cuenca sedimentaria, donde se registran casi todas las fortalezas. Se trata de la herencia de una organización socio-espacial previa, de época musulmana, donde el dominio por parte del aparato central andalusí era dispar en cada zona, al mismo tiempo que eran distintos los tipos de aprovechamiento de la tierra y del poblamiento por parte de las comunidades, pero también influye la dinámica feudal y colonizadora y las opciones señoriales. La persistencia de los castillos durante este período se divide en tres fases. La primera sería el control del territorio por parte de la monarquía castellana, que utiliza los castillos como puntos de asentamiento de su poder. Pasado el peligro almorávide, se produce una segunda fase que es la cesión de los castillos a los señores y su conversión en puntos de formación de señoríos, perdiendo las fortalezas buena parte de su función habitacional ${ }^{126}$. Una tercera fase es la consolidación del sistema feudal, donde los castillos dejan de ser un elemento esencial, ya que no se adaptan a las necesidades productivas y no sirven como elementos señoriales en el marco del poder jurisdiccional, por lo que el papel central recaerá en las villas. Sólo aquellos lugares que consiguieron reformularse como villas sobrevivieron, pero dejaron de ser meros castillos ${ }^{127}$.

124 TorRes Balbás, L., "Castillo de Fuentidueña»; CARRero Pérez, L.M. a , El castillo y la villa de Fuentidueña del Tajo, Madrid, 1990, pp. 64 y ss.; SÁEz LARA, F., «Catálogo», pp. 162-169.

125 De hecho, el propio fuero parece poner de manifiesto la existencia de un concejo de Fuentidueña previo sin una estrecha relación con el castillo, la cual se establece mediante el fuero pero en unos términos de vinculación señorial: «E por que labredes e reapredes el dicho castillo cada que cumplier e mester fuer et nos acoiades a nos el dicho maestre en él cada que y llegarmos yrado e pagado, e después de días de nuestra ida, que acoiades en él al que fuer maestre la Orden de Santiago con Dios e con Orden"; Rivera Garretas, M., La encomienda, doc. 245.

126 Como recientemente ha señalado BosselLIER, S., Naissance, pp. 143-144, la dominación castral en los primeros tiempos de la conquista cristiana y de la reorganización social del espacio el castillo es importante ya que es un «símbolo de poder» que se adapta al señorío.

127 Un desarrollo muy similar se observa en la Transierra de Extremadura, especialmente en las zonas más septentrionales, BERNAL ESTÉVEZ, Á., Poblamiento, transformación y organización social del espacio extremeño (siglos XIII al XV), Mérida, 1998. 
El estudio de la zona serrana ofrece la posibilidad de observar una evolución en la que los castillos no juegan ningún papel en el proceso feudalizador. En realidad, son las villas y las aldeas los elementos espaciales dominantes en el paisaje social de la Transierra madrileña en el siglo XIII y a veces, como ocurre con Segovia, la villa es exterior a la región. Por tanto, el protagonismo de los castillos se reduce a los primeros momentos de la reorganización social del espacio madrileño. Su función, lejos de ser un mero apéndice militar de un engranaje más amplio, se centra en el dominio señorial. Quizás es entonces cuando más se pueden acercar al modelo del incastellamento, ya que son centros de poder señorial que sirven a la colonización del espacio. Pero no son núcleos habitacionales importantes, a excepción de ciertas villas posteriores, que pierden su condición de mera fortaleza. Por tanto, es muy difícil hablar de un incastellamento de la zona, a lo que se une el hecho de que el número de castillos es bastante bajo, frente a lo que ocurre en determinadas regiones de Italia ${ }^{128}$, por lo que es lícito replantearse el papel que ha jugado este fenómeno en la consolidación del feudalismo de un área «mediterránea».

128 Así, sólo en la Toscana se han localizado 2.212 castillos para toda la época medieval; Francovich, R. «Introduzione», en Francovich, R. y Ginatempo, M. ${ }^{2}$ (eds.), Castelli. Storia e archeologia del potere nella Toscana medievale. Volume I, Florencia, 2000, p. 9. De todos modos, el estudio de la región madrileña en comparación con otras áreas del Mediterráneo será objeto de un próximo análisis. 